Western University Scholarship@Western

1970

\title{
Interprovincial Migration and Economic Adjustment
}

Thomas J. Courchene

Follow this and additional works at: https://ir.lib.uwo.ca/economicsresrpt

Part of the Economics Commons

Citation of this paper:

Courchene, Thomas J.. "Interprovincial Migration and Economic Adjustment." Department of Economics Research Reports, 7008. London, ON: Department of Economics, University of Western Ontario (1970). 
RFSEARCH REPORT 7008

INTERPROVINCTAL MIGRAT ION AND

ECONOMIC ADJLSTRIST

$b y$

Thomas J. Courchone

$=$

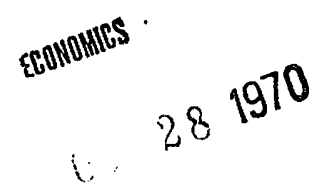

It is a pleasure to acknovledge the splendid research assistance rendered by John Parikhal and Gordon Cameron. Valuable comments on earlier drafts from my colleagues Kevin Burley and David Conklin and our graduate students are likewise gratefully acknowlerged. The twenty pages of referee's conments were extremely useful in :edrafting the paper but, unfortunately, the limits of space and time did not enable all their suggestions to be incorporated. Support for research assistance was provided by the Canada Council and the Department of Regional Economic Expansion.

Apri1, 1970 
Interprovincial Migration and Economic Adjustment

by

Thomas J. Courchene

\section{Introduction}

Problems relating to regional economic disparity are becoming more and more the focal point of Canadian economic policy. Not only do these regional disparities evoke policy measures directed specifically toward regions but their presence also impinges on the types of policies that can be prescribed for other economic ills. For example, the current overriding concern with inflation cannot be viewed withcut reference to regional disparities. With inflation proceeding at a rate of 4 percent in 1968, for example, appropriate monetary and fiscal policy might call for a curtailing of aggregate demand. But with unemployment rates alrady well over 7 percent in the Atlantic region such a policy would push unemployment rates to an unacceptable level in this region (if indeed they are not already at an unacceptable level). In a recent article McInnis highlighted the seriousness of this regional disparity:

over the period 1926-1962 taken as a whole, the level. of variability of relative per capita income among regions has been approximately constant. Furthermore, over the long term, there has been little change in the relative positions of the individual regions. On the basis of this evidence the trend of regional income differentials in Canada appears to have been roughly a constant; there has 1 been neither convergence nor divergence. [1968, p. 441].

This raises several important questions: What are the avenues through which regional adjustment proceeds? How adequate are these channels? What is and what ought to be the role of government (provincial and federal) in the

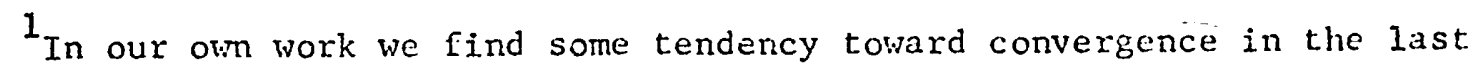
decade [Courchene, part 5]. But this does not detract appreciably from McInnis' generalization, 1970. 
adjustment process? While an analysis of the chemels and aciequacy of regional adjustnent is beyond our scope, it is, nevertheiess, the appropriate context within which to investigate interprovincial migration--the furpose of this paper. As juteresting as a stucly of migraion of and by itself mily be, throughout this paper the analysis of migration vill be consirlered as a means toward achieving a more important goal, wanely econonic adjustment or the efficient allocation of resources. For this reason we shall, where possible, focus on movements of the labor force rather chan the entire population, precisely because the former is more relevant to economic adjustment.

In a country as large and diverse as is Canarla $j$ t would be surprising indeed if the process of general economic growth did not imply differences in the rates of growth in differont regjons. Changes in the strusture of consumer demanc, changes in technoloby and the discovery or now sources of natural resources are bound to have djeferential impacts on reyional Ecoibmic growth. In order that economic adjustment proceed, resoures rili have to be realiocated goographically. Furthermore, the rezional intes of populition growth may be such as to contribute further to the adjustment pronier. Since labor is the most imporiant factor of production (in the sense that it accounts for roughly two-thirds of the cost of prociucine the flow of final goods and services) it is not unreasomable to expect ii to bear the Iion's share of tlis adjustment. ${ }^{2}$ Labor-force adjustment takes place a: a!I levels--local, intraprovincial, interprovincial, and irtermationa, In this

${ }^{2}$ Adjustment of course need not imply geographical mobilj.ty. Occupational mobjijty and skill-upgrading of labor are also important facets of the adjustiment process. 
paper our focus is on inlerprovincial inigration oniy, even though the intraprovincial movements, For example, are considerably greater in magnitude. ${ }^{3}$ In this sense our analysis presents, at best, on 1 y a partial picture of the role of: migration in economic adjustment. ${ }^{4}$

The paper j.s divided into five majn sections. In Part II we sketch some elements of the basic theoretical apparatus that underly the analysis and then procecd to develop the hypotheses that form the Eramework for the empirical investigation. Since most of the theory is readily available elsewhere, our treatment of it will be very bief indeed. Part III looks into various issues regarding the data sets and definitions of variables. The empirical thrust of the paper is contained in sections IV and $V$. In the former we prescnt a cross-section regression analysis of inteiprovincial labor-force movements by age and by level of education based on data from the 1901 Census ot Canada. Section $V$ present's both crossmsectior and timeseries results based on data from sixteen years of interprovincial migration of family allowance recipients. Part $v$ lnaws some implications from the analysis relating to economic adjustment and suggests areas for future research.

II. Labor Force ifigration: Some Theoretical Issues

Basic to the theory relating to interprovincial labor-force migration is the idea that labor is a factor of: production. Efficient allocation of

${ }^{3}$ For an excellent study of intraprovincial mobility of the Canadian popilation which focusses on cultural and demograpiric, as well as economic motives, see stone [1.964].

4Even at: the level of interprovincial mobiljty we are neglecting emigration and imigration. For some aspects os imigriation and adjusiment the reader can consult Parai [1965]. 
resources requires factors seeking out those opportunities where their return (appropriately defined) is greatest. If there is no cost tc relocating, then focussing on the differential returns of various jobs is sufficient to deternine the direction of factor mobility. But there are costs to mobility and especially to interprovincial mojility since this involves geographical dislocation. Therefore factors will terd to move where their net return (benefics minus costs) is greatest. Alternatively we can, following sjaastad [1962], treat migration as an iavestment in human capital where the costs of this investment are the present value of foregone earnings plus any money and non-money costs directly associated with migration and the return to the investment is simply the discounted present value of future earnings arising from migration. Neturally, investment in human capital in the form of migration should proceed if the present vaiue of returns exceeds this cost.

As stated, both these approaches to migration amount to not mich more than economic truisms. Most of this section rill be cievoted to isolating variables that can be expected to impinge on either the costs associatej with, or returns derived from, migration, thus converting the inderiying theory into a series of testable hypotheses. Except for the age-related hypotheses which fit more naturaliy into the human-capital framerork, the hypotheses that follow are consjstent with either approach. Some of these hypotheses will not be very novel. For example, the hypotheses that inte:provincial mobility is positively related to differential provincial incomes and negatively related to distance have already received impressive empirical support [Vanderkamp, 1969]. Indeed, Vanderkany's theoretical anaiysis is cast in a benefit-cost framework and the present päper can be viewed as an extension of his work. 
Since wages are the return to labor, the prine determinan of Iabor-force migration on the benefil side should be relative wage rates in the various provinces. Mnwever, wo not attenpi to construct arepresentative wage rate at a provincial level. Rather, we utilize income data to approximate the average yearly earnings per voller. In a study for the Economic Council, Denton [1966] develops what we consider to be an appropriate proxy for wage income, namely easned income per employed person. Earned income is defined as those portions of provineial personal income associated with employment, i.c., labor income, military pay and allowances, and the net income of unincorporated business proprictors, including farmers. This total is divided by the labor force less the yearly average number of unemployed persons. In other words, if the average unemployment rate in province $i$ is 4 percent, the denominator, i.e., employed persons, equals

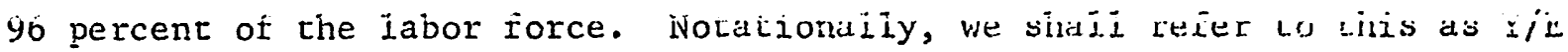
where $\mathrm{Y}$ is earned income and $\mathrm{E}$ is the average number of employed persons. Letting $i$ represent the sending province and $j$ represent the receiving province, we have:

Hypothesis I: Migration from province $i$ to $j$ will be positively related to $\left(Y_{j} / E_{j} /\left(Y_{i} / E_{i}\right)\right.$, i.e., to relative labor incomes.

Based on the work of Vanderkamp (1969) there is considerable evidence to suggest that the earned-incone-per-enployed-person variables ought to be included separately in a regression equation. Specifically, Vanderkamp argues that, given $Y_{j} / E_{j}$, a lower level of $Y_{i} / E_{i}$ might not increase migration from $i$ to $j .5$ on the one hand a decrease in $y_{i} / E_{i}$ will increase the

5 Indeed, Vandcrkamp's empirical results suggest that a decrease in $Y_{i} / E_{i}$ will decrease migration from $i$ to $j$ [1969, Table 1 ]. 
relative wage differential and on this count stimulate migration, but on the other hand it wj.11 also lower the gereral level of income in region $i$ and tend to make peoplc less able to bear the cost of job relocation. We view this argument as a capital-inarket-distortion argunent. One could argue that if capital markets were perfect the potential migrant would be able to borrow to finance this investment, and there would be no reason to act differently toward an increase in $Y_{j} / E_{j}$ than a decrease in $Y_{i} / E_{i}$. But the markets for human capital are far from perfect. Accordingly we formulate Hypothesis II: An increase in $Y_{j} / E_{j}$ will increase the rate of migration fron $i$ to $j$. A decrease in $Y_{i} / E_{i}$ wi.j.1 also lead to movements froin $i$ to $j$. In absolute value, however, the coefficient for $\mathrm{Y}_{j} / \mathrm{E}_{j}$ will be larger than that for $Y_{i} / E_{i}$.

Some of the empirical work in this paper will relate to hypothesis I and some to hypothesis II.

By themselves, relative wages (represented by $\left(Y_{j} / E_{j}\right) /\left(Y_{i} / E_{i}\right)$ ) do not capture adequately the ccomomic attraction of the various provinces. For example, British Columbia has the highest level of earned income per employed worker in Canada. However, it also has one of the highest rates of unemployment in Canada. It is important that this latter variable be allowed to influence interprovincial migration. Ceteris paribus, the greater the unemployment rate in the receiving province, $U_{j}$, the smaller will be the migration flow to $j$. Accordingly

Hypothesis III: The unemployment rate in the receiving province, $U_{j}$, will be negatively ielated to migration froin $i$ to $j$.

Analogously, for any given level of $\mathrm{Y}_{i} / E_{i}$ the greater the unemployment rate in the sending region, $U_{i}$, the greater will be the outmigration rate from 
that region. Tit may be true that an increase in unemployment also serves to inhibit migration because the potential migrant (if unemployed) may be deprived of a sourec of income to finarce the direci costs of moving. However, the indirect cost of moving (i.e., the foregone earnings) is zero so that the net recurn to investment is a.11 the higher. Since the latter effect will, in our opinion, prevail ve formulate

Hypothesjs IV: Migration from $i$ to $j$ will be positively reialed to $U_{i}$

Focussing still on the benefit sida we want to incorporate into the analysis the level of uneajned incone per meraber of the labor force. We are not interested in this paper in non-labor incomes such as dividend income, even though these will obviously affect the decision to migrate. Rather we are interested in the governinent-transfer type of unearned income. Within this framework we specity three difterent types of varabies. Ine írst focusses on location-oriented subsidies or transfers only. As a proxy for this we utilize, for each province, the sum of statutory subsidies, equalization and stabilization payments, and the Atlantic Provinces Adjustment Grant under the Federal-Provincial tax-sharing arrangenents. Notationally we refer to these as $\mathrm{TG}$. Although these transfers do not go directly to persons but, rather, to provincial govermments they represent benefits to residents in the sense that thejr tax burdens are reduced accordingly. "We scale these transfers to each province, $\mathrm{TG}_{i}$, by the provincial labor force, $\mathrm{L}_{i}$. The greater the Ievel of these transfers per labor force, $T G_{i} / L_{i}$, the smaller will be outmigration from province $i$.

${ }^{6}$ A more complete analysis would, of course, include relative tax rates in the various provinces as a deteminant of interprovincial migration. This, too, is beyond the scope of: this paper. 
Hypothesis V: Migration from i to $j$ is negatively related to the level of intergovomental transter payments per worker of sending resion, $T G_{i} / \mathrm{L}_{i}$.

Since the level of these transfers is generaily inversely related to the level of per-capita income of the provinces, it j.s quite possible that they will have some effect in decreasing the provincial disparity in $Y_{i} / F_{i}$. If this is the case, then the effect of transfers will be captured indirectly in the relative wage variables (assuming hypothesis $I$ is verified). Hypothesis $V$ seeks a direct test of the jmpact of $\mathrm{TO}_{i} / \mathrm{L}_{i} \cdot$

For the time series data set relating to mizration of family allowance recipients we employ total federal transfer to province i, notationally $\mathrm{IT}_{i}$, rather than $\mathrm{TG}_{i} \cdot{ }^{7}$ Because of the differing income levels in the various provinces a given dollar trarefer of funds per member of the lahor fares will he "honrth" more th a low insome province than to a high income province. Accordingly we saaled $\mathrm{TT}_{i}$ not by $\mathrm{L}_{i}$ but by $\mathrm{Y}_{i}$ so that the transfer variable becomes relative transfers, i.e., $\mathrm{TT}_{i} / \mathrm{Y}_{i} \cdot$ For the family allowance data set, then, hypothesis $V$ will read: Migration from $i$ to $j$ is negatively related to the relative transfers to province $i, \operatorname{TT}_{i} / Y_{i}$.

Thus fa: we have been assuming that the opportunity cost of being unemployed is the wage rate. But in reality the oppostunity cosi $i$ : the wage rate minus the benefit rate under the unemployment insurance program. The larger are the rates of unemployment compensation, the lower will be the cost of being out of work and the less the tendency to migrate. This

${ }^{7}$ Research on the two data sets was separated in time by several months. Data on total transfers vere cbtained after the section IV empirical work was completed but prior to the research on the family allowance data. No attempt was made to incorporate $\mathrm{TG}_{i} / \mathrm{T}_{i}$ into the Section $\mathrm{V}$ equations. 
is Hypothesis VI: The greater the levej of unemployment insurance benefits in province $i, i . e ., U T_{i} / Y_{i}$, the smaller will be the outnigration from $i{ }^{8}$ In sumiary then, outmigration from provirce $i$ is hypothesized to be positively related to the rate of unemploynent in province $i$ (hypothesis IV) and negatively related to the rate of unemployment compensation in province $i$ (hypothesis VI).

- Turning now to the cost side of interprovincial migration, distance is the principal variable we empioy to represent the direct money costs involved in migration. Nearly all empirical studies find a negative correlation between the rate of migraticn and the distance moved, other things being held constant. In addition, nearly all the studies indicate that the marginal cost of each additjonal mile implied by the regression equations far exceeds the actual transportazion cost for an adiitional mile. This jimplies that distance serves as a proxy for other costs, money and non-money, that are likely to be associated with distance (e.g., the cost of returning home for a visit or in case of an energency increases with distance; infornation concerning job opportunities probably decines with distance; the greater the distance, the greater the degree to which family, commuity and cultural ties will have to be broken). Hypothesis VII. then, is: The rate of migration from $i$ to $j$ is negatively related to distance from $i$ to $j$, $n_{i j}$

Migration From province $i$ to $j$ is positively related to the education

8 A detailed analysis of the relationship between unemployment insurance payments and interprovincial migration is thr subject of a separate paper. [Courchene, 1969]. We sha11 touch on this hyothesis cnly very briefly in this paper and only in connection with the farnily allowince data set. Note that we again scale unemployment transfers by income in province $i, Y_{i}$, rather than by labor force, $L_{i}$. Results of cruations embodying $\mathrm{UT}_{i} / \mathrm{L}_{i}$ are availabie in Courchene [1969]. 
level in province $i$. This is Hygothesis VIf. Sufficient evidence already exists on the positive contribulion of education to nigration ${ }^{9}$ so that we need not defend hypothesis VIII. But we car carly the anaysis somewhat further. It has become standard procedure in migration studies to focus on the income-distance tracie-off, i.e., the ratio of $\left(Y_{j} / \mathbb{E}_{j} /\left(Y_{i} / E_{i}\right)\right.$ to $D_{i j}$. Education tends to encourage migration because it increases the benefits as well as decreases the costs of moring. For chample, insofar as more education provides the potential migrent with greater knowledge concerning employment opportunities in other provinces, education scrves to increase the benefits of migration. Another way of stating this is that geographical size of the labor market increases with increasing education. But insofar as any cultural or provincial ties lessen with greater education, or the risk of becoming unemployed after moving decreases with greater education,

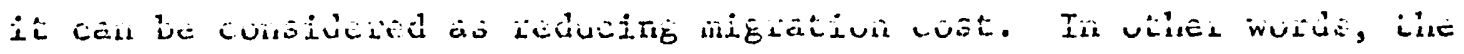
greater information that accompanies greater education provides the potential migrant with more knowledge of $\mathrm{Y}_{j} / \mathrm{E}_{j}$ and also serves to decrease the information and other costs associated with distance. Accordingly, we propose:

Hypothesis IX: The greater the level of education, the greater will be the income-distance trade-off.

A subset of the census data kindly suppliea by $\mathrm{Dr}$. Jeroy Stone permits us to deveiop hypotheses relating to age and migration. Viewing migration as an investment in human capital and taking a life-span earnings as the relevant return it is clear that for a given income differential the

9For example, see Schwartz [1968, cil. V.] for the contribution of education to li.S. migration and Stone [1969] for the influence of education on Intraprovincial population movements. Note that while we shall measure education in terms of formal. schooling, it may well be a proxy for skill level. We make no attempt to distinguish between thesc two. 
benefits from migration will be greater the younger the migrant (assuming, of course, that our relative incone variables are decent proxies for relative life-span eamings between $:$ and $j$ ). In addition the costs of moving are likely to increase with age. On this point Schwartz notes:

A few cost elements which vary systematically with age are the following:

1. Al1 the cost elements which are associated with the size of family (and size of family is clearly a function of age). ...

2. The cost of losing the experience in giving lip past

"on the job training". ... and the cost of new training.

3. The psychic cost: which is also probably a function of age. [1968, pp. 56-7].

Assuming that income differentials represent the primary returns to migration and distance reflects the primary cost, this leads us to formulate:

Hypothesis X: The impact of provincial income differentials on migration is negatively related to the age of the migrant.

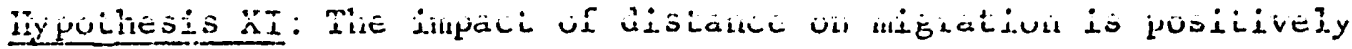
related to the age of the migrant.

We now turn to some determinants of migration not based directly on optimum resource allocation grounds. In a related study, McInnis [1969] suggests that for some provinces the movement of people from rural to urban centers takes the form of interprovincial migration. In particular, he was referring to the prairie provinces and P.E.I. We generalize this observation and assume that the process of urbanization is likely to cross interprovincial boundaries for those provinces which are largely "rural". Specifically, we assume that the percentage of the labor force employed in agriculture is a good proxy for the degree $1: 0$ which a province can be classified as "rural" and formulate

Hypothesis XII: The rate of migration from $i$ to $j$ is positively related to the percentage of labor force of province $i$ that is employed in agriculture. 
The remaining variables that we consider are nore on the cultural level. Previous studies, e.g., Stone [1969], have show that the Quebec labor force is considerably less mobile than that for the rest of Canada. Viewed somewhat differently, the above variables will overpredict outmigration from Quebec. The combination of cultuid, language and religious elements are probably at the base of this phenomenon. But even this low outmigration may be consistent with a human capital approach. As Becker [1964, pp. 28-9] suggests "j.f specific (...that is, to the firms, industries or countries [provinces] in question) training were important, differences in earnings would be a misleading estimate of what migrants could receive." At any rate, we allow for this by including a dumny variable for outmigration from Quebec. Relatedly, the migration from the four Atlantic provinces to Ontario is far greater (based on the regression results that follow) than the simple cost-benefit model we specity would indicate. In large measure, this results again because reasons of a cultural-1anguage nature inhibit their migration to Quebec. This effect too will be allowed for by the use of a dummy variable, i.e., the dummy variable will have 5 observations equal to unity and the remaining 85 will be zero. Four of these values of unity will relate to outmigration from each of the Atlantic provinces to ontario while the fifth will relate to outmigration from New Brunswick to Quebec, once again capturing a non-economic (language) motive for migration. The third and final dummy variable we employ is to take account of the tremendous outmigration from Saskatchewan to Alberta--over 4 percent of the Saskatchewan labor force moved to Alberta during the 1956-61 period (Table A.1). All of the dummy variables enter the equation as intercept durmies. A more realistic use of these variables would surely have been to allow them to enter the 
equations as slope dumies. But the primaty purpose of including them was to increase the explanatory power of the various models so more sophisticated specifications were not, in our opinion, warranted. We hasten to add that none of the conclusions reached in this paper is affected by the inclusion of these dummy variables.

The two remaining issues that we wish to address require data for several years so that they relate only to the family allowance data set. Firstly, is the time pattern of migration becoming more responsive to such variables as sending and receiving region income? Casual empiricism suggests that information regarding employment opportunities and incomes in other provinces is increasing over time. In addition, transportation costs are declining, at least relative to incomes. We propose, as Hypothesis XIII that interprovincial migration is proceeding with increasing efficiency

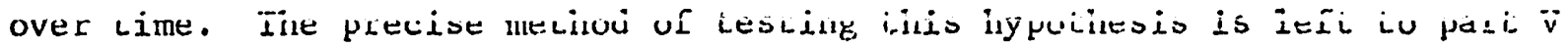
of this paper. The remaining area for investigation is the response of migration to the level of overall economic activity, represented by the Canadian unemployment rate. In a previous study Vanderkamp suggests that "unemployment has a significantly negative effect on the volume of mobility between regions" (1968, p. 594) and further that "this relationship is not adequately captured by regional unemployment differentials" (1968, p. 594). This is Hypothesis XIV and, along with the previous hypothesis, will be examined in part $V$ of this paper.

The Form of the Estimating Equation

What is the appropriate dependent variable in an interprovincial migration analysis? Should one focus on gross or net flows? Should the flows be in absolute terms or in rates? From the manner in which the various 
hypotheses are phrased, it should be clear to the reader that we intend to focus on the outflows from each province to every other province. Moreover, since we are interested in isolating the deteminants of migration it is appropriate to focus on the gisoss outflow from each province because it is the province of departure that decisions to luave are taken. ${ }^{10}$

Rather than use the absolute gross outflow, we divide this outflow by the relevant parent population in province $i$ (labor force for the census data and family allowance population for the data set on family allowance migration). Again, one can quarrel with this procedure. Vanderkamp, for example divides the gross outflow from $i$ to $j$ by the sum of the parent population in $i$ and $j$. Implicit in this latter procedure is the assumption that if the population in each province were doubled, gross outflows vould quadruple whereas the former implies a doubling of the outflows. In a study of U.S. migration Schwartz [1968, Appendix I] concludes that both these polar cases are deficient but, if one has to choose, standardization by the parent population of the sending province is preferable. The dependent variable, then, is the rate of outflow from each province to every other province. Intuitively, it appears to us to be more satisfactory than the Vanderkamp procedure. ${ }^{11}$

${ }^{10}$ Vanderkamp [1969] also focusses on gross ontflows. However, McInnis [1969], in his analysj.s of 1961 census data, employs net migration as the dependent variable. By his own admission his results are not very encouraging. In part, we feel that this can be traced to the choice of net migration as the dependent variable. Note that McInnis also uses population movements while we have argued that labor-force data are more appropriate (where available) for a study of migration as an economic variabie.

${ }^{11}$ Consider two provinces $i$ and $j$ where $j$ has a labor force ten times as large as that for $i$. Assume also that 9 percent $c$ f province $i$ 's labor force migrates to $j$ and 1 percent of $j$ 's labor force migrates to $i$. Under our procedure, the rates of migration for $j$ and $j$ would simply be $q$ percent and 1 percent respectively. Under the Vanderkamp formulation the migration 
For most of the empirical section we employ the simplest types of models-all variables enter in a lincar or log-linear fashion. Because the census data, when classified by age, involve cells with zero gross outflows for certain provinces the linear version is used almost exclusively for this data set. The log-linear specification of the model is employed for the family allowance transfer data set. For both data sets, however, we include results obtained from other specifications including that employed by Vanderkamp.

III. Data

We employ two basic data sets. The first consists of the interprovincial labor-force migration between al.1 pairs of provinces. Data are directly from Table J.4 of the 1961 Census of Canada monograph 4-1-10. This set is classified by age. ${ }^{12}$ For both total labor-force migration and the age subclassifications, then, we have 90 observations. To investigate the interrelationship among education, age, and migration, we obtained a subset of the Census data from Dr. Leroy Stone of the Dominion Bureau of Statistics. (Note that these data were developed by Dr. Stone and not by D.B.S.). This data set is for male migration in each of two age groups (25-34 and 35 and over) classified by two levels of education--elementary and less, and greater than elementary. In this subset the four Atlantic provinces are lumped together into one "region" so that the data contain 42 rather than 90 observations.

from $i$ to $j$ would be .8 percent while that from $j$ to $i$ would be .9 percent. (Both these numbers are rounded). In other words, despite Vanderkamp's attempt to avoid the use of net migration, his procedure would show a greater percent flow from $j$ to $i$ than from $i$ to $j$ precisely because the net flow from $j$ to $i$ is positive.

${ }^{12}$ It is also classified by other categories such as sex and unemployment status in 1961. Except for the age classification, we ignored the other classifications. 
The second basic data set consists of monting observations of interprovincial mioration family allowence recipients over the sixteen years from 1952 to 1967. These monthly dat.a were sumned to obtain annual observations. For each year, then, there are 90 observations and for the pooled data set we have 1,440 observations.

The dependent variable for the Census data is the gross flow of labor-force migrants $\overrightarrow{F r o m ~ p r o v i n c e ~(o r ~ r e g i o n) ~ i ~ t o ~ p r o v i n c e ~(o r ~ r e g i o n) ~}$ $j, M_{i j}$, divided by the labor force of province $i, L_{i}$, i.e., $M_{i j} / L_{i}$. For the family allowance data set the dependent variable is family allowance migration from province $i$ to $j, F M_{i j}$, divided by the family allowance population in province $i, \mathrm{FP}_{i}$, i.e., $F M_{i j} / F P_{i}$. Thie definition of the explanatory variables is as follows:

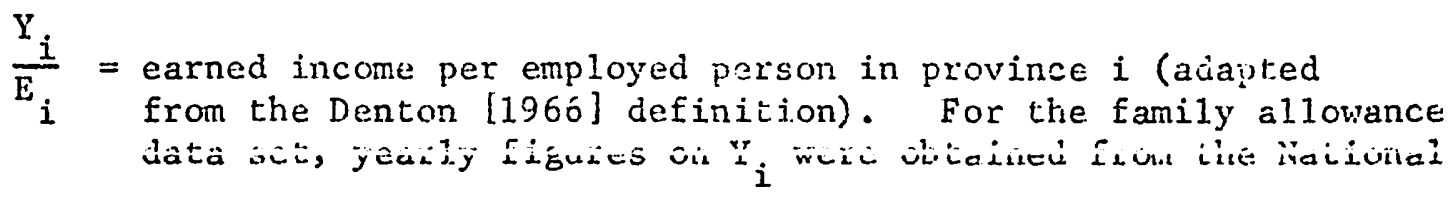
Accounts. For the Census data set we used the average over the 1957-1960 period. Figures are expressed in thousands of dollars per employed worker. For the family allowance data, these incomes are deflated by the consumer price index.

$$
\frac{Y_{j}}{E_{j}}=\begin{aligned}
& \text { earned income per employed person in province } j \cdot \text { Derived } \\
& \text { similarly to } Y_{i} / E_{i}^{\prime}
\end{aligned}
$$$$
\frac{Y_{i} / E}{Y_{i} / E}{ }_{j .} \quad \begin{aligned}
& \text { relative earned income per employed person in provinces } j \text { and } i \\
& \text { (a proxy for relative wage earnings). }
\end{aligned}
$$

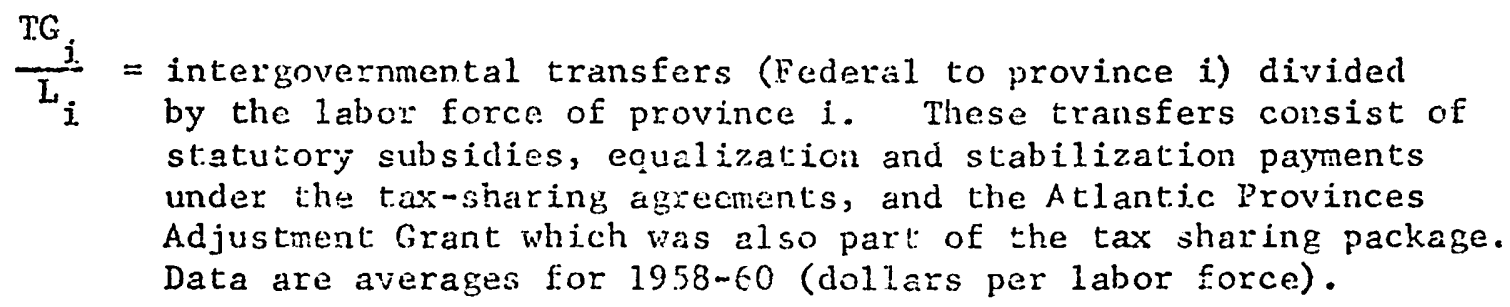




$$
\begin{aligned}
& \frac{\mathrm{TI}_{\mathrm{i}}}{\mathrm{Y}}=\text { total fecieral transfers to province } i \text { divided by earned } \\
& U_{i}, U_{j}=\text { unemployment rates in provinces } i \text { and } j \text {. For the Census } \\
& \text { for the 1957-60 period. Annual figures are employed for } \\
& \text { the family allowance data set. For some provinces figures } \\
& \text { were obtained from the Labour Division of D.B.S. } \\
& \frac{U T_{i}}{Y}=\text { unemployment transfers to province } i \text { divided by earned } \\
& \text { income of province } i \text {. Uremployment transfers are the sum } \\
& \text { of both seasonal and regular payments t:o residents of } \\
& \text { province } i \text {. Source: Annual Roports on the Benefit Periods } \\
& \text { Established and Terminated under the Unemployment Insurance } \\
& \text { Act, D.D.S. 73-201. } \\
& E_{i}=\text { level of education in province } i \text { (detined as the percent of } \\
& \text { the labor force having an education beyoni grade 10). } \\
& \text { Source: Census of Canada. } \\
& A_{i}=\text { percent of the labor force employed in agriculture in province } i \text {. } \\
& \text { Source: Census of Canada (D.B.S. 99-S22, Table 5). } \\
& D_{i j}=\text { distance from province } i \text { to province } j \text { (defined as distance } \\
& \text { between major cities in thousands of miles). } \\
& \mathrm{S}_{1}, \mathrm{~S}_{2}, \mathrm{~S}_{3}=\text { shift variables. } \mathrm{S}_{1} \text { is unity for outmigration from the Atlantic } \\
& \text { provinces to ontario and also for outmigration from New } \\
& \text { Brunswick to Quebec. } \mathrm{S}_{2} \text { is unity wherever the dependent } \\
& \text { variable is outmigration from Quebec. } S_{3} \text { is unity for out- } \\
& \text { migration from Saskatchewan to Alberta. For all other } \\
& \text { observations, the shift or dummy variables contain zeros. }
\end{aligned}
$$

Prior to turning to the empirical results we encuurage the reader to devote some time to the two tables in the Appendix of this paper. Data in both these tables are from the Census data set. Table A.1 contains the total (i.e., summed over all age categories) outmigration rates for the 
provinces. The last columin of the table presents the overall outmigration rate for each province. These outmigration ratios are the dependent variables in the empirical work in part IV. Table A.2 is included for information purposes only. It presents interprovincial flows, the total net outflow for each province and the net outflow as a percent of the labor force. Note that only ontario, Alberta, and British Columbia were net gainers over the 1956-61 period. For a valuable description of the time pattern interprovincial flows covering most of this century, the reader is referred to McInnj.s [1969].

\section{Airing Some Deficiencies}

It seems appropriate, at this juncture, to point out some of the many deficiencies that beset both our data sets and our methodology. The Census data compare residence in 1961 with that in 1956. To the extent that Iong distance migration proceeds via a series of short moves, the Census data will overestimate long moves. Furthermore, migration away from province i after 1956 and back to province $i$ before 1961 will be missed completely. The family allowance data set excludes single people and married couples without children--the more mobile groups of the population.

Many of our variables, such as the various transfer variables, appear only for province $i$ and not for province $j$. This is partly justified since we are focussing on the determinants of outmigration and the decision to migrate is made in province $i$. A more complete analysis, however, would also include these variables for province $j$, the receiving province. Undoubtedly, there is a considerable degree of interdependence among some of our explanatory variables, e.g., income, education, and unemployment. And so on. Cavalierly, we simply ignore these problems. 
We now turn to the empirical results. Iypotheses I to XII wiIl be addressed in section IV wich deals with the Census data. The regressions from the family allowance data set appear in section $V$ while the results relate primarily to Hypotheses XIII and XIV they will also provide further evidence on the first twelve hypotheses.

\section{Empizical Results: Census Data.}

Table 1 contains various regression equations all employing total $\mathrm{M}_{i j} / \mathrm{L}_{i}$ as the dependent variable. Tables 2 and 3 present results for twc different equations for each of the age categories as well as total migration. Table 4 equations relate to the data set classified by age and education. Bracketed figures beneath the regression coefficients are t-values. Unless otherwise indicated, all variables enter the equation in linear form. We ask the reader's indulgence as we work our way through the results and the manner in which they impinge on our various hypotheses. Our initial focus will be on Table 1.

Equation 1 clearly substantiates, for this data set, the familiar result that migration is positively related to relative wage or income differences and negatively related to distance, i.e., clearly confirms Hypotheses I and VII. Equation 2 indicates that the higher the level of education in province $i$ the greater is the outmigration for that province (Hypothesis VIII). The non-economic factors, represented by the shift variables $s_{1}, S_{2}$, and $S_{3}$ are highly significant, so much so that the explained variance in equation 3 is double that for equation 1 . When education is added to this equation, the $\mathrm{R}^{2}$ increases to a very respectable 0.82 (see equation 4). Note that with education in the equation the Quebec dummy variable, $S_{2}$, is no longer significant. For virtually all 


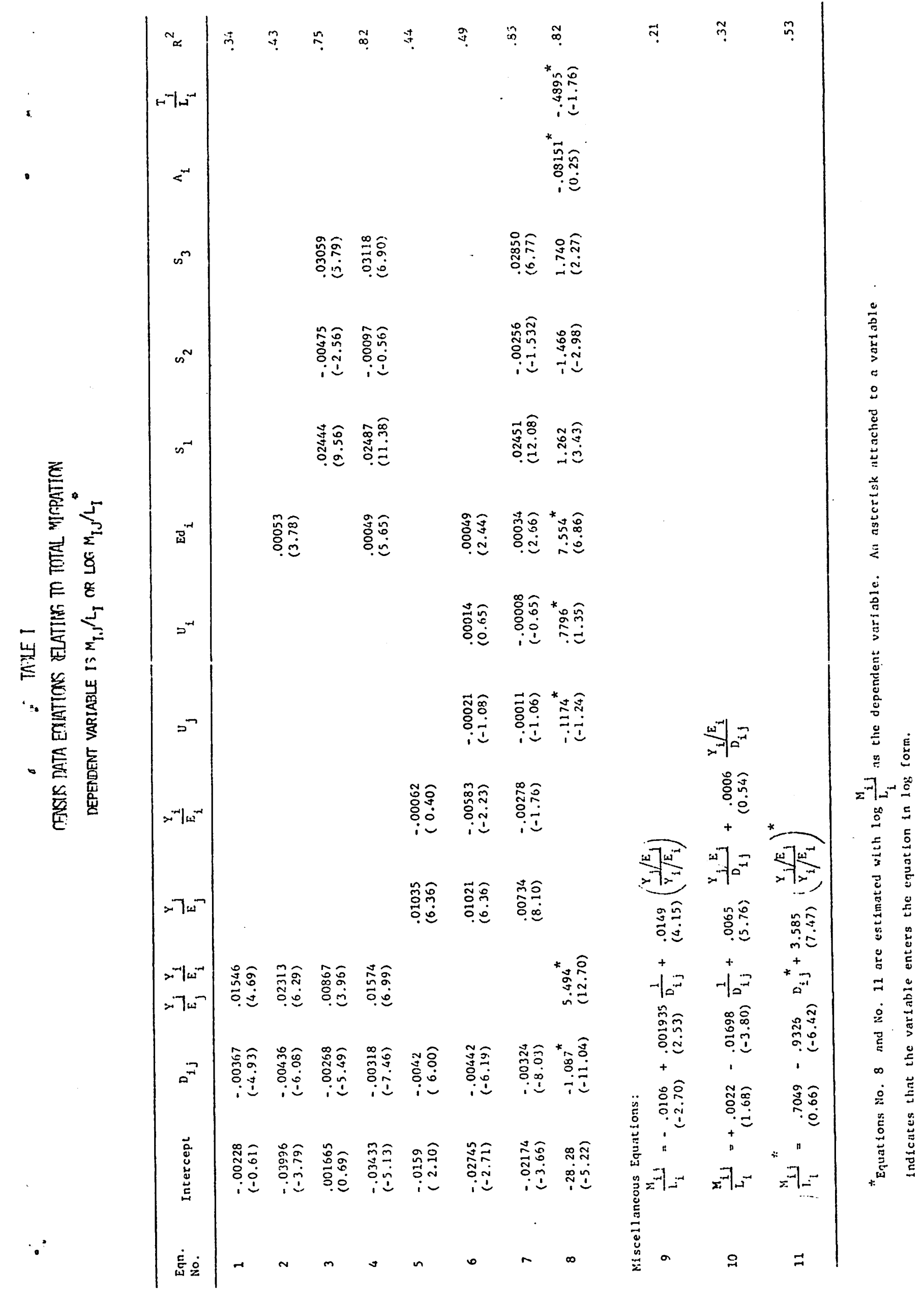


Census data equations which include education as well as the shift variable $S_{2}$ this same result occurs (see the Table 3 equations, for example). It appears then that the very low outmigration rates for Quebec (see Table A.1) that we attempted to capture via a dumny variable can be accounted for in part by the low education level in that province. Turning to equation 5 where $Y_{j} / E_{j}$ and $Y_{i} / E_{i}$ appear separately, tire results confirm Vanderkamp's contention that income of the sending and receiving regions affect migration differently (Hypothesis II). Specifically, an increase in earned income per person in province $j$ exerts a str positive influence on migration from $i$ to $j$. Earned income in the sending region does not acquire a significant coefficient in this equation. However, in other equations (c.g., equation 6 , Table $I$ and the total migration equation in Table 2) the coefficient for $Y_{i} / E_{i}$ is negative and significant. Furthemcre, it is sinaller in absolute value than the coefficient for $Y_{j} / E_{j}$. The correct specification of the migration equation does indeed seem to call for $Y_{i} / E_{i}$ and $Y_{j} / E_{j}$ entering separately-at least for the formulations of the migration model employed in this paper. We might also point out that with education included in the equation, $\mathrm{Y}_{i} / \mathrm{E}_{i}$ tends to acquire a more significant coefficient.

Hypotheses III and IV imply that the coefficients for $U_{j}$ and $U_{i}$ should be negative and positive, respectively. The coefficient of $U_{j}$ does not enter the census data equations with a significant coefficient. But, as the reader can readily verify, in every equation in which $U_{j}$ does occur it acquires the appropriate (negative) coefficient (see Tables 1 and 3 ). We interpret this sign consistency as lending considerable support for Hypothesis III. Even though the evidence relating to $U_{i}$ is ambiguous in 
Table 1, the results from Table 3 for the various age groups as well as for total migration clearly confirm Hypothesis IV: autmigration from province $i$ is positively related to the unemployment rate in province $i$. Based on. both coefficient size and $t$-values it appears that migration from $i$ to $j$ is affected more by $U_{i}$ than by $U_{j}$-just the opposite of what holds for $Y_{j} / E_{j}$ and $Y_{i} / E_{i}$

\section{Migration and Age}

We now turn to an analysis of the impact of age on migration. The column labelled "means" in Table 2 presents the average rate of outmigration for each age group. Migration rates peak in the 20-25 and $25-29$ age grcups and decline thereafter. The 45-64 and over 65 age categories have migration rates considerably below the 15-19 age group. The specification in Table 2 has income of the sending and receiving provinces entering separately rather than in ratio form because this, as we shall see, permits a fuller analysis of the relationship between age and income. All age groups respond strongly (in terms of t-values) to income per vorker in the receiving region, $\mathrm{Y}_{j} / \mathrm{E}_{\mathrm{j}}$. In fact, the behavior of this coefficient across age groups corresponds closely to the age pattern of the mean of $M_{i j} / L_{i}$-peaking at $20-24$, reinaining at this level for $25-29$ and then falling continually over the rest of the age groups with the 15-19 coefficient substantially greater than that for 45-65 and 65 and over. But the intriguing pattern is that exhibited by sender-region income, $Y_{i} / E_{i}$. For the three youngest age groups, $Y_{i} / E_{i}$ acquires a significant negative coefficient. Except for the $35-44$ category the remaining coefficients are not statistically significant and for the last two age groups the coefficients fall drastically. In fact, for the 65 and over category $\mathrm{Y}_{i} / \mathrm{E}_{i}$ acquires a positjve coefficient.- Even more 


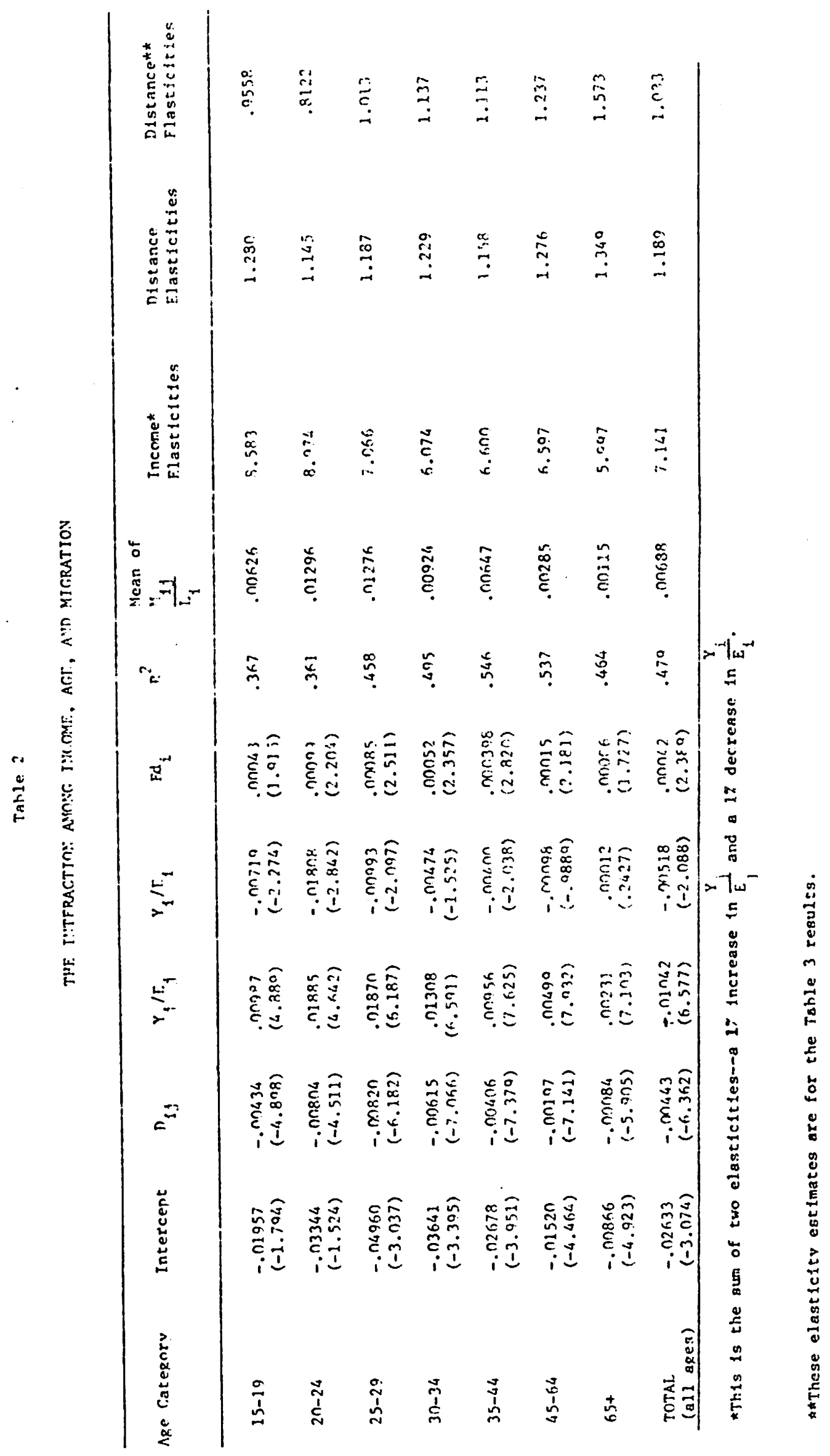


interesting is the fact that for the first two age groups the coefficient for $\mathrm{Y}_{i} / E_{i}$ is roughly of equal. magnitude (a1though oppositely signed) as that for $\mathrm{Y}_{j} / E_{j}$. For the remainder of the age groups (again excepting 35-44), the ratio of $\mathrm{Y}_{j} / \mathrm{E}_{j}$ to $\mathrm{Y}_{i} / \mathrm{E}_{i}$ increases with age. The 20-24 age group, then, is quite indifferent whether the cause of the relative income differential is a rise in $Y_{j} / E_{j}$ or a Fall in $Y_{i} / E_{i}$ : the coefficients for these variables are equal in absolute value. This behavior is entirely consistent with Hypothesis $X$. Since the young have the most to gain from higher wages elsewhere they should be the most responsive to changes in relative wage levels, regardless of the source.

We attempt to measure this responsiveness of migration to income by calculating an elasticity which takes account of both receiving and sending region incomes. Specifically, we present in column 9 of Table 2 the sum of

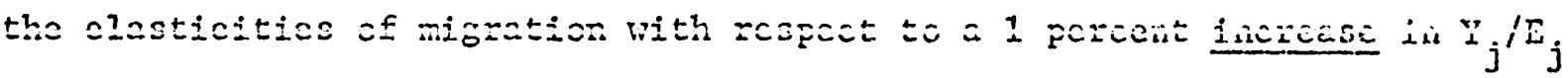
and to a 1 percent decrease in $Y_{i} / E_{i}$. These elasticities are calculated at sample means. The three largest elasticities are for the three youngest age groups and the lowest is for the oldest age group. On balance, then, our empirical results lend considerable support to Hypothesis X. Further investigation of the age-income-migration relationship should look into the impact of such things as family formation, housing, and company transfers and their inter-relationship with age and migiation. Treatment of these factors is beyond the scope of this paper.

The rationale behind Hypothesis XI is that the costs (both money and non-money) of migration will increase with age. Perhaps the tendency for sending province income to affect migration less over the age spectrum is a reflection of the greater cost of moving (with reasoning akin to that leading up to Hypothesis II.) But the variable with which we elect to test 
Hypothesis XI is distance, $D_{i j}$. Elasticities of migration with respect to distance appear in the second-last column of Table 2. Except for the fact that the elasticity is greatest for the oldest age group, no obvious pattern emerges. The last column of Table 2 presents elasticities derived from the $D_{i j}$ coefficients of the full model (i.e., Table 3 ). Here a more consistent pattern emerges--the elasticities tend to increase with age-thus providing sorne confirmation for Hypothesis XI.

The Full Model

Table 3 presents estimates for results for the "full" model for both total migration and the various age categories. One glance at the ccefficients for $T G_{i} / L_{i}$ and $A_{i}$, indicates that both Hypothesis $V$ and XII receive solid empirical verification. The greater percentage of the labor force employed in agriculture in province $i$. the greater the oucmigracion from province i. Far more important, insofar as the process of econonic adjustment is concerned, is the consistently negative coefficient on federal intergovernmental transfers to province $i, \mathrm{TG}_{i} / \mathrm{I}_{i}$. These equations lend support to the proposition that such transfers inhibit migration flows. Nearly two decades ago $A$. D. Scott argued this very proposition: ...the maximum income for the whole country, and so the highest average personal income, are to be achieved only by maximizing national production. This in turn can be achieved only when resources and labour are combined in such a way that the marginal product of similar units of labour is the same in a 11 places. An increase will result when labour is transferred from places where its marginal product is low to places where it is high... . Such a labour transfer can come about in two ways. The first is by means of controlled labour allocation, either with or without the additional hribes of free transport to new places of work. The second results from the existence of real wage (amenity) differences between the two areas such that the worker can better his lot by moving to an area where the bundle of 


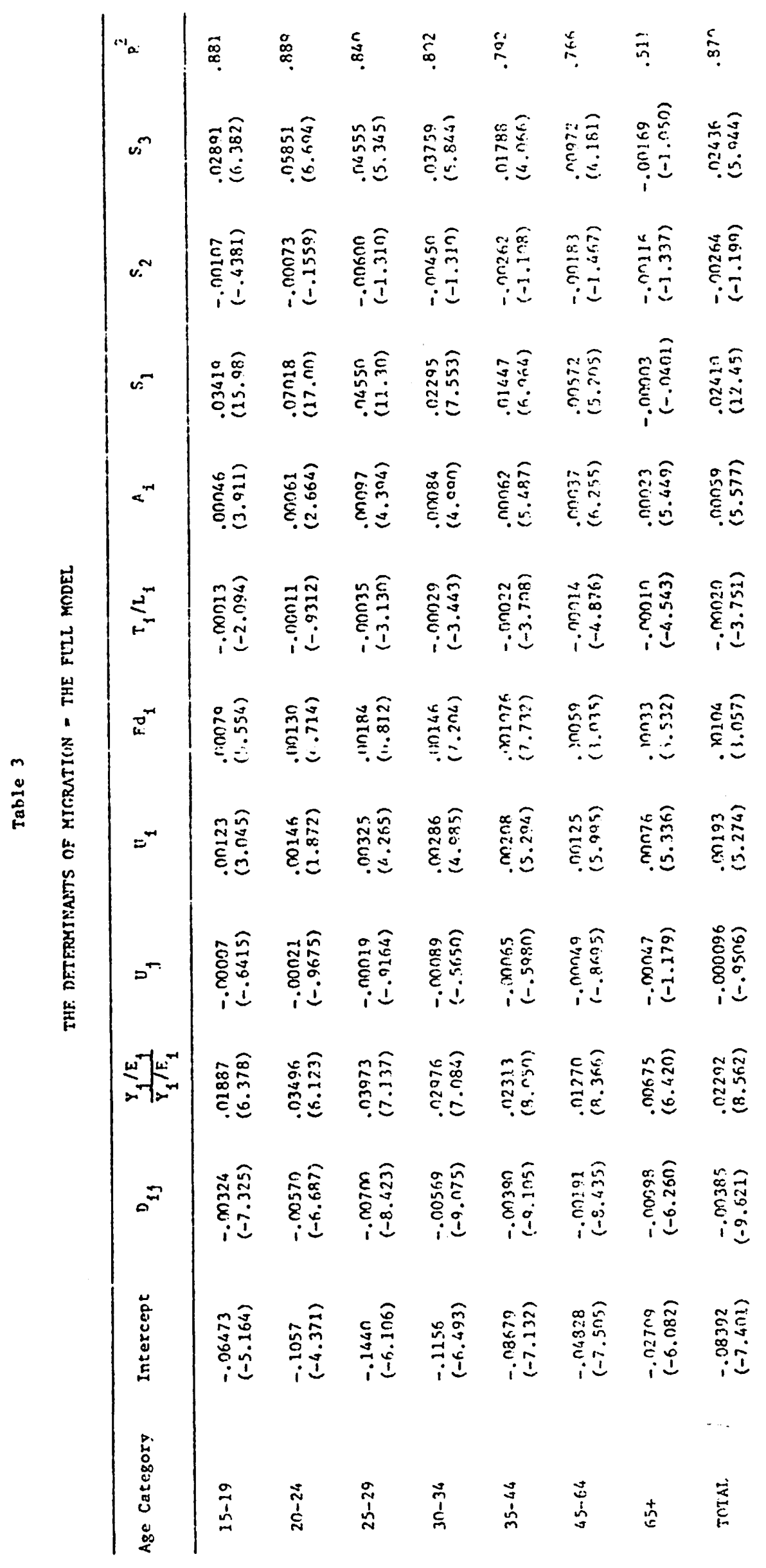


amenities received in return for his labour plis those received as a right of local citizenship is sreater than the bundle in his former home. It is contended here that transfers of government income from place to place counteract this incentive to labour mobility and thus prevent the maximization of mational production. [1950, p. 419].

Much more in the way of both analytical and empirical work needs to be done on this question. Hopefully our results will kindle an interest in this research.

The consistency of the Table 3 results over the various age groups is remarkable. We leave the reader the task of satisfying himself on this score. Note that for total (a11 ages) outmigration our model succeeds in explaining nearly 90 percent of the interprovincial migration rates over the 1956-61 period.

\section{Migration and Education}

Table 4 presents regression equations for the education-classified data set obtained from Dr. Stone. Our prime interest in these results is to investigate the impact of education on the income-distance trade-off. We have already established that education is positively related to migration. For both the 25-35 and 35-and-over age groups the t-value of the income coefficient increases substantially relative to that for distance for the higher educated class. More importantly, the income-distance ratios (presented in the last column of Table 4) are substantially greater for each of the age categories for the higher-educated group in each class (i.e., 4.39 vs. 2.88 , and 4.52 vs. 3.16). This evidence confirms Hypothesis IX. In addition, note that the trade-off is increased more for the younger age group, consistent with Hypothesis $\mathrm{X}$ relating to the behavior of migration and age. 


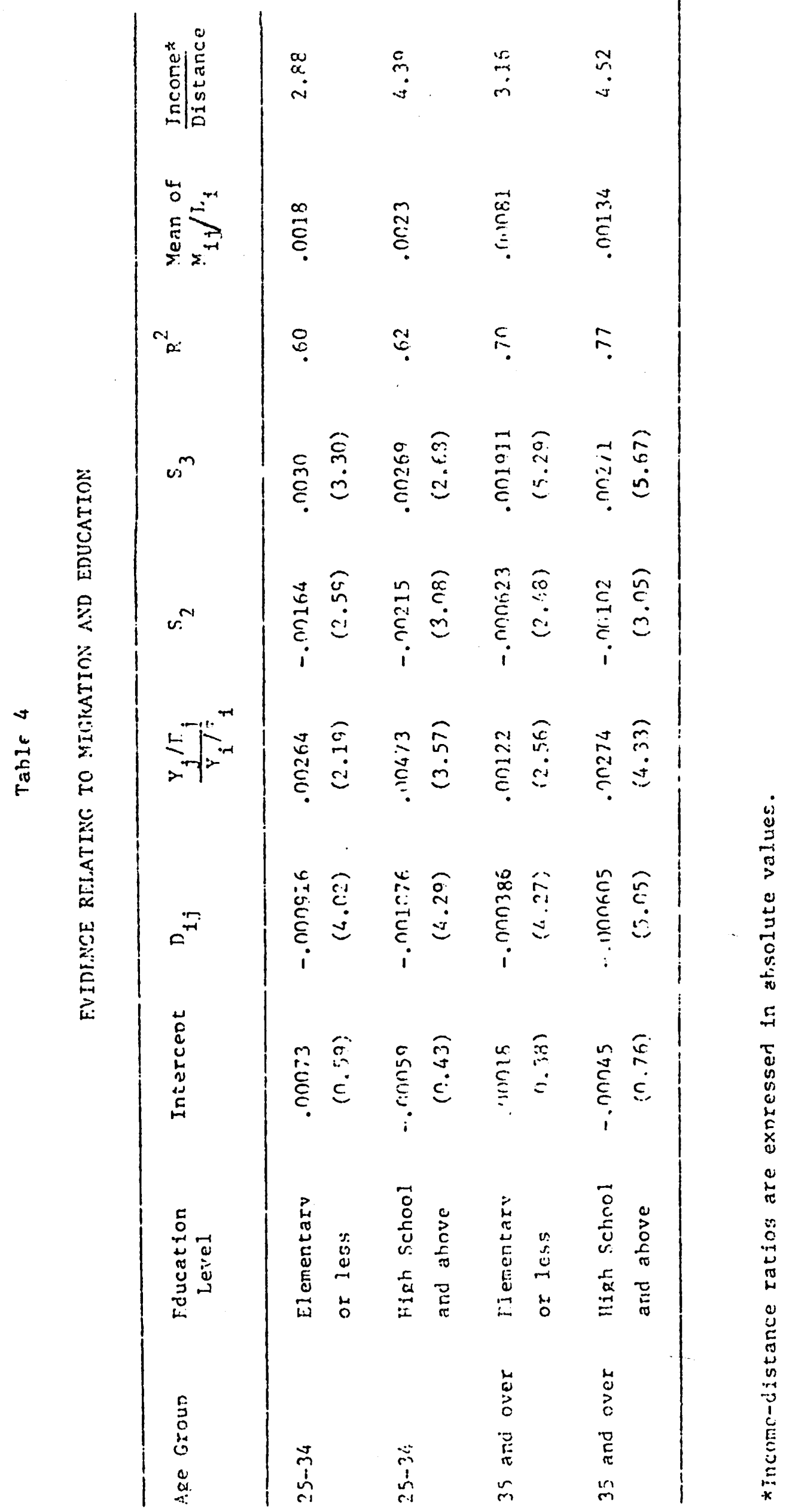


Some Alternative Specifications

Al1 the equations referred to thus far have had the variables entering in a simple linear fashion. But there is goci reason to expect that there are important non-linearities involved in the migration decision. For example, it seems unreasonable to expect that it would take the same dollar increase in $Y_{j} / E_{j}$ to encourage a migrant to move an extra 100 miles when he has already moved 100 miles than when he has already moved 1000 miles. Vanderkamp attempts to account for this by specifying his variables standardized by distance. Equation 10 of Table 1 shows the results of an equation embodying the explanatory variables in Vanderkanp form. (Note, however, that the dependent variable is $\mathrm{M}_{i j} / \mathrm{L}_{i}$ and not the Vanderkamp dependent variable $\mathrm{N}_{i j} /\left(\mathrm{L}_{i}+\mathrm{L}_{j}\right)$ ). In terms of $R^{2}$, this equation does not fare as well as the comparable linear specification (equation 5 of Table 1 ).

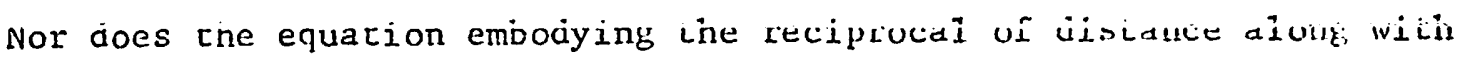
$\left(Y_{j} / E_{j}\right) /\left(Y_{i} / E_{i}\right)$ fare as well as a simple linear formulation (compare equations 1 and 9 of Table 1 ).

However, estimating equation 1 in log-linear form yields an equation which, in terms of t-values and overall goodness of fit is superior to equation 1. (See equation 11). The coefficient (elasticity) of distance is approximately unity implying that a 1 percent increase in distance vill decrease migration by 1 percent, other things constant, so that an incremental 100 miles added on to an intended move of 100 miles will be a greater deterrent to migration than will an incremental 100 miles added to an intended move of 1000 miles. Equation 8 of Table 1 is the log-linear counterpart of the total migration equation of Table 3 . In terms of $t$-values the log-linear formula indicates a smalle: role for $U_{i}$ and $\mathrm{TG}_{i} / \mathrm{L}_{i}$ than the linear specification. Income and distance play a more 
dominant role in the log-1incar equation with incollic now acquiring the largest t-value. The coefficient of $a_{i}$ is not correctly signed, let alone significant. Education still renatins very significant but the influence of the dummies (except for $\mathrm{s}_{2}$ ) declines markediy. Because of the presence of zeros for some cells in the age-classified migration matrix we focussed almost exclusively on the linear specifications for the Census data. No effort was expended in estimating alternative specifications for the log-linear model. Therefiore, equation 8 is to be interpreted as a replication in $\log$ form of the Table 3 specification and not the result of any search procedure. In the next section, however, most of the equations vill be estimated in logarithmic form. We now turn to these results.

\section{Empirical Results: Family Allowance Data}

Tables 5 and 6 contain regression results for interprovincial migration based on the family allowance data set. Table 5 presents yearly results for a straightforward multiplicative version of our migration model. Table $\epsilon$ presents equations estimated from the "pooled" data set (all years 1952-1967). The primary purpose of the Table 6 results is to focus on the temporal behavior of migration (Hypothesis XIII), and to investigate the effect of the overall level of unemployment on the tendency to migrate (Hypothesis XIV). However, prior to analyzing the results as they pertain to these two hypotheses, we shall focus on the Findings in Tables 5 and 6 insofar as they are able to add new evidence relating to the hypotheses already discussed in the previous section.

First of all, the Table 5 specification performs very well for all years. It is clearly evident that income in the receiving and serding 
Table 5

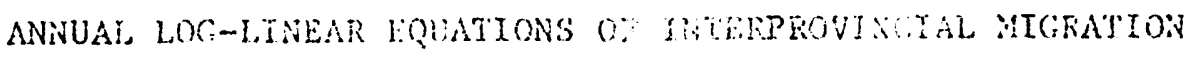

FAMLIY ALLOWALCE MATA SET

$\ln \frac{F M_{i}}{F P_{i}}=B_{1} \ln \frac{Y_{1}}{E_{i}}+\beta_{2}$ in $\frac{Y_{i}}{E_{j}}+B_{3} \ln E_{i}+\beta_{4} \ln y_{i j}+\alpha_{0}+\alpha_{1} S_{1}+a_{2} S_{i}+a_{3} S_{3}+e_{1}$

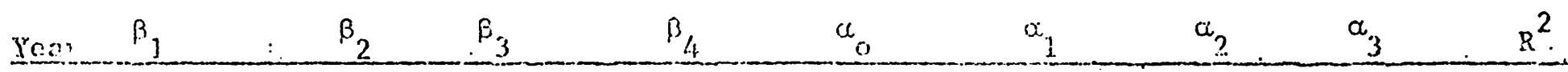

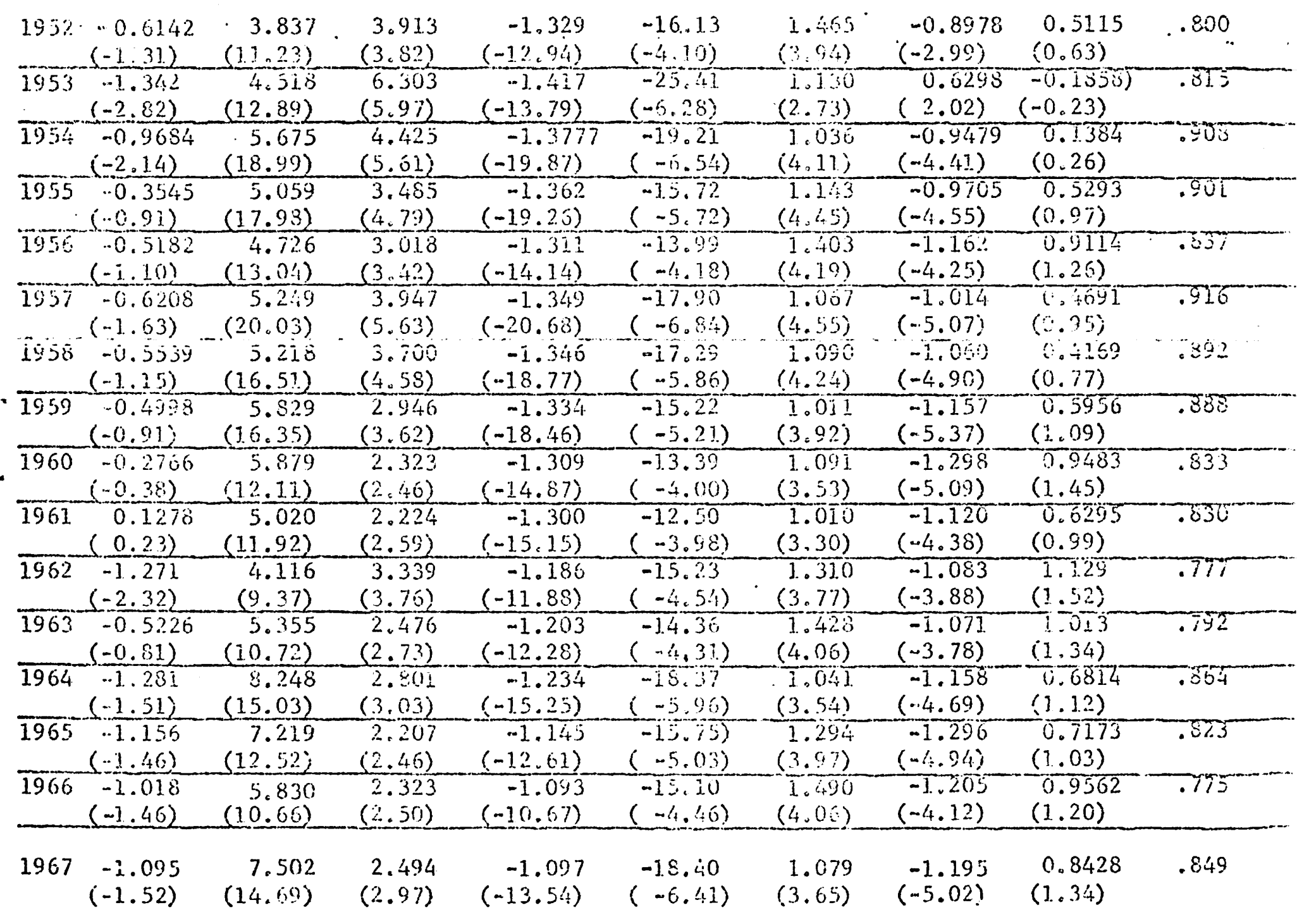

Notes: Dollar values are in nominal terms. Estimation $i$ in real terms would affect only the intercepts. 
regions affect migration differently. Therefore, while hypotheses I $\because: n$ be substantiated empirically, ${ }^{13}$ the ratio form of the jucone variable coln ceals important informalion relating to tine response of migration to anoriz. In the previous section, there was some ambiguity conceming the relutionship of $Y_{i} / F_{i}$ to outmigration from province $i$. It was clear (and is aledi from lable 5) that the coefficient for income of the receiving region exceeds that for the sending region. But is the coefricient of $Y_{i} / i_{i}$ positive or negative? In Table $5, \mathrm{Y}_{i} / \mathrm{E}_{i}$ acquires a negative coefficient for $\mathrm{i}$ t of the 16 years, and for eleven of the years the t-value is unity or gidate. For the pooled data, however, sending region income does acquire a iy significant negative coefficient--see equation 1, Tahle 6 . This neidrit and significant coefficient for $\mathrm{Y}_{i} / E_{i}$ also obtains for the Iine:ir veisicia of the modeI (equation 2, Table 6) and indeed holds ihroughout the vinicus

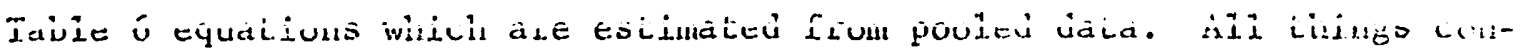
sidered, we are prepared to say that Hypothesis II is confirined: migieidon from $i$ to $j$ is negatively related to the level of income in province $i$; aiti positively related to the income of province $j$.

Equation 3, Table 6 is included primarily to lend empiriral supoct to Hypothesis VI: outmigration from province $i$ to $j$ will be negativeiy related to the level of unemployment insurance transfer paynents into partaze $\vdots$. The negative coefficient for $\mathrm{UT}_{i} / \mathrm{Y}_{i}$ is evidence $i n$ support of this hypothesis.

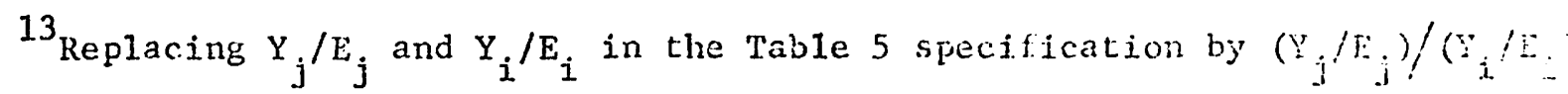
and re-estimating the equations yield coefficients for the incone vaidablt: that are positive and highly significant for each of the 16 years.

${ }^{14}$ Note that this variable is defined as unemployment tansfer py y. province $i$ standardized by the level of income in province $i$. An alteinatiye definition would be $U T_{i} / L_{i}$--unemployment insurance payments divided by the $1 \ldots .$. force. While both these variables acquire negative and significant cosiricients, the former acquires a larger t-velue. For an anitysis rif the adarise explanatory power of $\mathrm{UT}_{i} / \mathrm{I}_{i}$ versus $\mathrm{UT}_{i} / \mathrm{Y}_{i}$ see Courchene $[1969 \mathrm{j}$. 
This equation also lends support to Hypothesss III and IV: migration from $i$ to $j$ is positively related to the unemployment rate in province $i$ and negatively related to the memploynent rate in province j. Equation 3, then, reveals an interesting relationship between unemployment and migration. An increase in unempioyment in province $j$. vill tend to "jush" people out. But as unemployment insurance benefits increase (as a result of greater unemployment) this will tend to inhibit interprovincial migration.

Equation 4 of Table 6 (estimated in linear torms with the income variable in ratio form) extends this relationship somewhat by including a variable relating to total transfer income recejyed by province $i$. According to hypothesis $\mathrm{V}$ this variable should, and does, acquire a negative coefficient. It is interesting to note that the coefficient of $\mathrm{TT}_{i} / \mathrm{Y}_{i}$ is smaller (in absolute value) than that for $U \mathrm{IT}_{i} / \mathrm{Y}_{i}$, even though the latter is inclucied

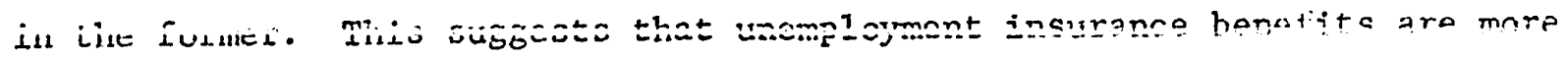
effective in inhibjting migration than are total transfers ecrewaliy. The total transfers variable also appears in equations 5 and 7 and provides evidence in support of our hypothesis that an increase in unearned as weli as in earned income in province $i$ will be negatively related to outmigration.

\section{Temporal Behavior of Migration}

Has the response of migrants to variables such as income and distance changed over time? The lable 5 results suggest that theire have indeed been changes in responses and that the changes are in the direction of increasing the extent to which migxation can be treated as an economic variable. The time pattern of the coefficients of $Y_{j} / E_{j}$, i.e., $\beta_{2}$, appears to be one of increasing elasticity. Likewise the elasticity of $Y_{i} / E_{j}$ also appears to be somewhat larger for the last half of the annual equations than for the 


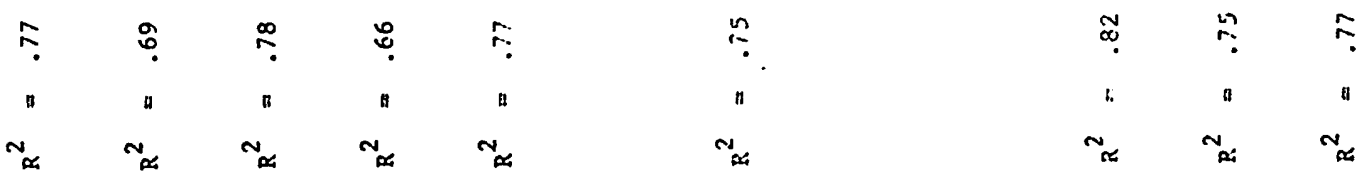

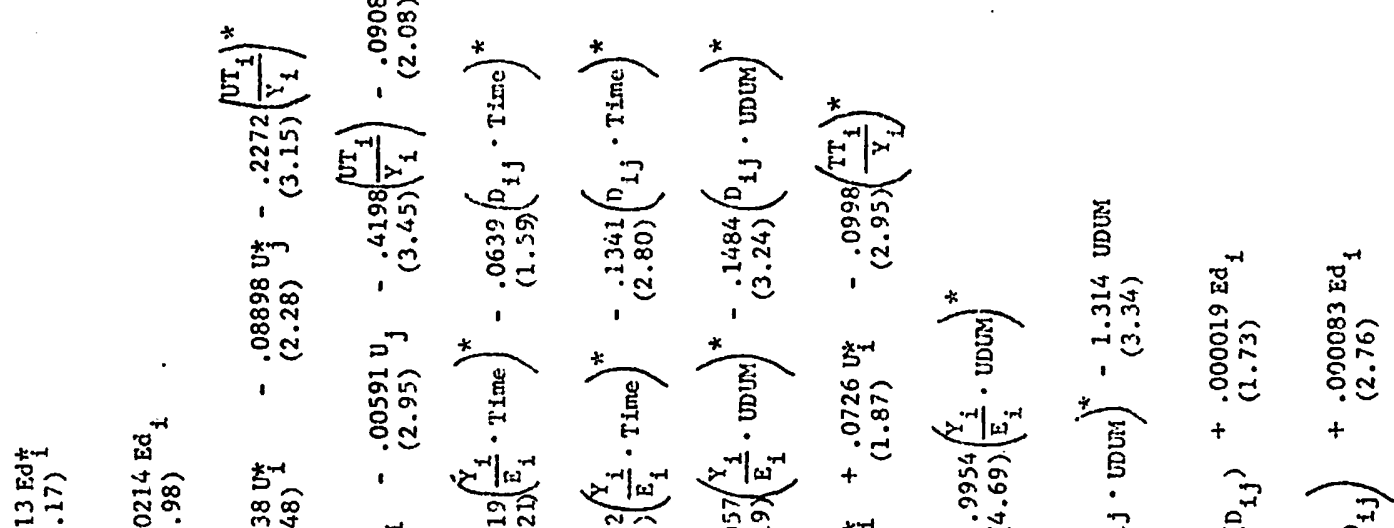

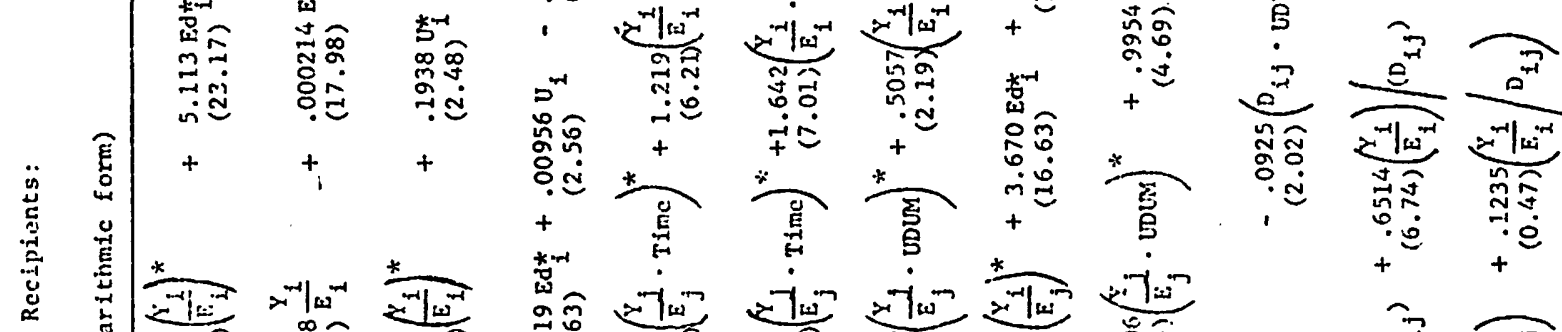

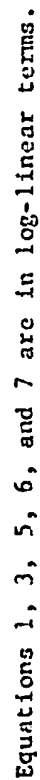

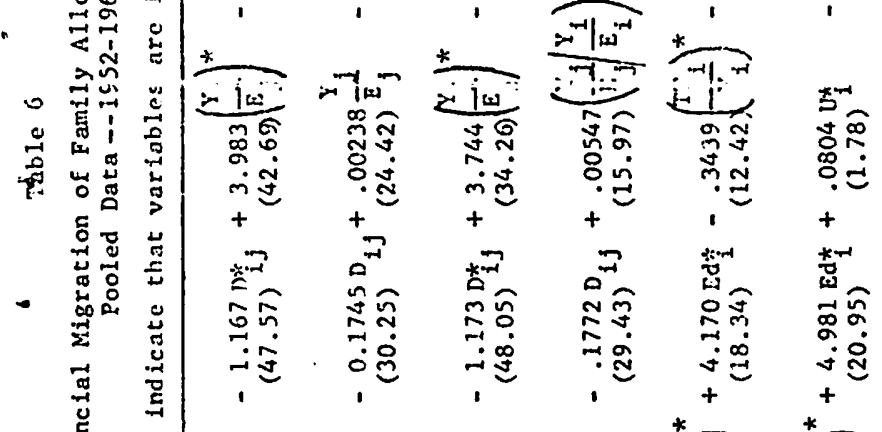

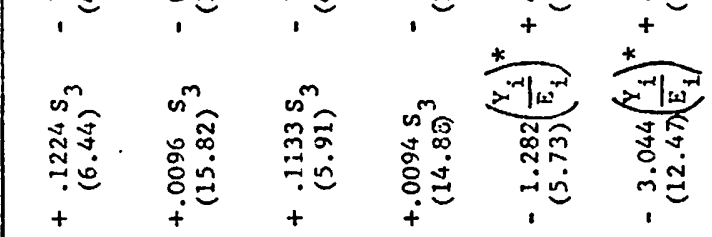

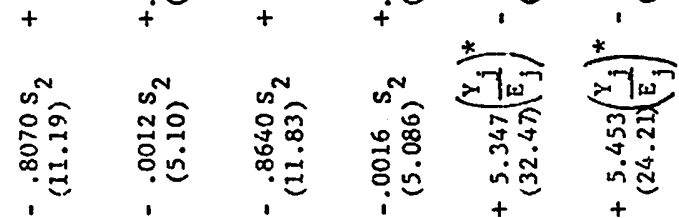

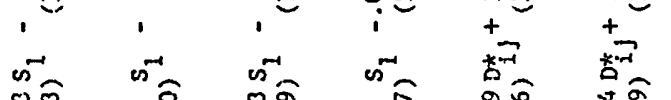

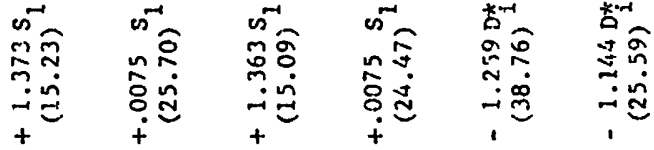

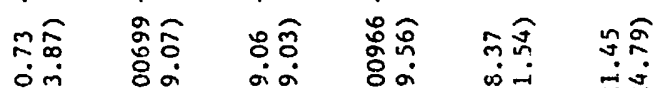

覀

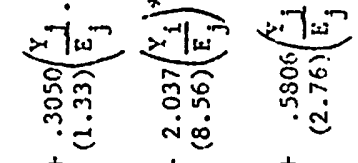

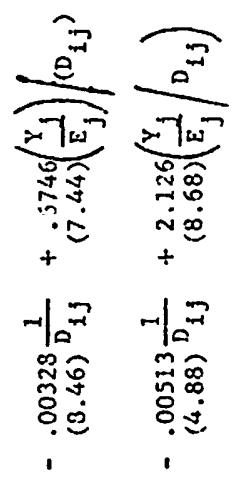

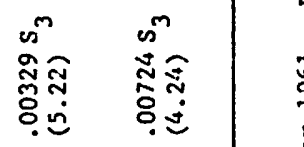

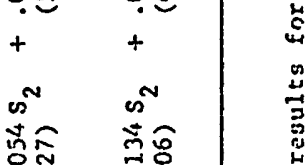

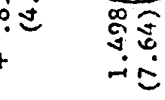

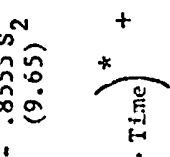

in

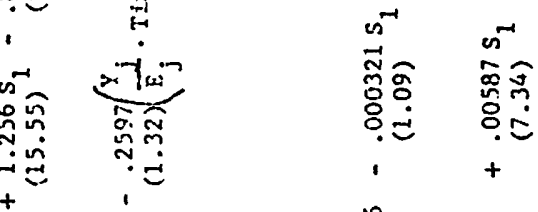

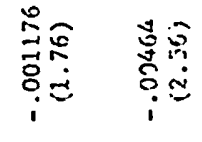

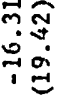

ن

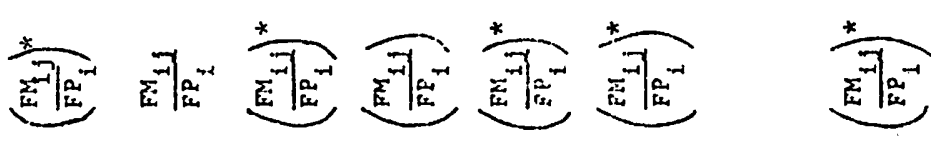

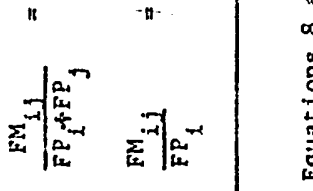

$\therefore$

$\dot{\infty} \dot{0}$ 
first half. For distance, the evidence is clearer silill. From 1950 to 1967 every distance elasticity is smaller than any that appears in the regressions prior to 1960.15

In equations 5, 6, and 7 of Table VI employ dumtry variables to isolate the temporal impact of income and distance in interprovincial migration. Specifically the coefficients of $\left(Y_{i} / E_{i} \cdot\right.$ Time $),\left(Y_{j} / E_{j} \cdot T i n i e\right)$ and ( $D_{i j} \cdot$ Time) represent slope (elasticicy) dummy variables for the first half of the data set (i.e., from 1952 to 1959). In other words, Time has a value of unity for all observations prior to 1959 and a value of zero thereafter. The value for the elasticity, say, for $D_{i j}$, for the first period then is the sum of elasticities $D_{i j}$ and ()$_{i j} \cdot$ Time). Focussing on equation 7 , for example, we note that for the period 1952 to $1959 \mathrm{Y}_{j} / \mathrm{E}_{j}$ has a lower elasticity, $Y_{i} / E_{i}$ has a larger (less negative) elasticity, and $D_{i j}$ has 2 njgner (more negalive) eiaslicily liall in lite lasi hair of lite peliui. Fitest results coincide with the rough impressions we drew from Table 5. The atraction power of the receiving province's income is increasing over time, but not by much. ${ }^{16}$ But the effect of sender region income is changing quite dramatically over time. In terms of point estimates, the elasticity of: migration with respect to $\mathrm{Y}_{i} / \mathrm{E}_{i}$ from equation 7 is -.539 for $1952-1959$ (i.e., $-2.037+1.498$ ) and -2.037 from $1960-1967$. Mj.gration is becoming more responsive to changes in the sender region income. Distance inhibits migration to a smaller degree for 1960-67 than fcr 1952-59. Phrased in

${ }^{15}$ In Table 5 the education elasticity clearly falls with time. In large part this occurs because we do not allow the education variable to acquire a different value each year. The percent of the lator force having an education of grade 8 or above in 1961 (Census) is used for 11 years. When we used cata from the last three Censuses to attempt to get an annual estimate of the education level in each province, the resulting elasticitics exhibited no definite time pattern. We do not show these results primarily because the education variable we constructed is of dubious quality, to say the least.

${ }^{16}$ The coefficient for $\left(\mathrm{Y}_{\mathrm{j}} / \mathrm{E}_{\mathbf{j}} \cdot \mathrm{T}_{\mathrm{in}}\right)_{\text {is }}$ is not significantly different from zero in equation 7, although it is signjicant jn equation 6 . 
another manner, for given values of all variables, the migrant will move further than previously. One reason for distance becoming less or: a deterrent over time is simply thet transportation costs have declined. Bit probably as important is the increase over time of information about job opportunities in other parts of the country. At any rate the results support Hypothesis XIII: migration is becoming more efficient over tine.

Migration and Aggregate Economic Activity

Concerning the relationship of the ovcrall level of unemployment (representing the level aggregate economic activity) and migration, Vanderkamp concludes:

The trade-off [hetween $\mathrm{Y}_{j} / \mathrm{E}_{\mathbf{j}}$ and $\mathrm{D}_{i j}$ ] is much more unfavorable (about 50\%) during depressed labor mirket conditions...than when unemployment is low... . In other words, mobility responds muct: less to existing opportunities when there is general slack in the labor market. 17

Our results, embodied in equations 6 and 7 of Table 6 , suggest a more complicated relationship between interprovincial migration and economic activity. The method we employ for isolating the impact of overall unemployment on migration is sjmilar to that adopted to investigate the relationship between time and migraticn. Specifically UDUS has a value of unity whenever the overall unemployment rate is above the average 1952-1967 level and a value of zero for those years when the aggregate unemployment rate is below this average leve1. In equation 6 , we note that the response of migration to $\mathrm{Y}_{j} / \mathrm{E}_{\mathrm{j}}$ is greater when the Canadian unemployment rate is above the 1952-1967 average. Furthermore, distance is more a deterrent to migration in high unemployment periods, i.e., the coefficient of $\left(D_{i j} \cdot\right.$ UDUM $)$ is negative. Vanderkamp is correct in suggesting that the trade off between $Y_{j} / E_{j}$ and $D_{i j}$

17 [1969, pp. 25-26]. Vanderkamp makes these observations on the besis of: annual regression equations of the type represented by equation 8 of Table 6 . 
(i.e., the ratio between $Y_{j} / E_{j}$ and $D_{i j}$ ) is worsened jn high unemployment years. But the response of migration to $Y_{j} / I_{j}$ is in the direction of improving the trace off. The trade off is rorsened because, during periods of high unemployment, $D_{i j}$ imposes a proportionally greater restraint on migration than the impecus given by $Y_{j} / \mathrm{R}_{j}$. Once again, however, the impact of sender region incone on nigration during high unemployment periods is more important than that of the receiving region income. In equation 6 the elasticity of outmigration to $\mathrm{Y}_{i} / \mathrm{E}_{i}$ is approxinately -3.0 for normal periods and -2.5 for high unemployment periods. In other words, if income falls in province $i$ by 1 percent during "normal" periods, outmigration will increase by 3 percent. Linder high-unemployment periods a 1 percent fall in $Y_{i} / E_{i}$ will result in an increase of only 2.5 percent in cutmigration. This is consistent with the analysis earlier in the paper to the effect that in

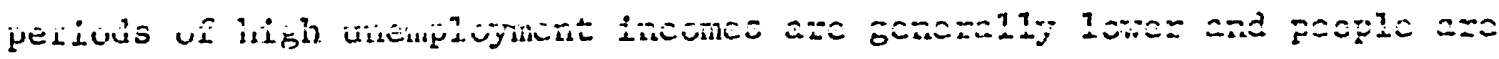
less able to afford to move. It is also consistent with the results relating to distance: moves that do take place during high unemployment puriods will tend to be over shorter distances.

Equation 7 differs from equation 6 because in 7 we allow the intercept as well as the slopes of $Y_{j} / E_{j}, Y_{i} / I_{i}$, and $D_{i j}$ to be affected by the level of aggregate economic activity. ${ }^{18}$ While the effect of high unemployment on the slopes of the three variables $Y_{i} / E_{i}, Y_{j} / E_{j}$, and $D_{i j}$ is in the same direction as in equation 6 , it is no longer true that the trade off between $Y_{j} / W_{j}$ and $D_{i j}$ is worsened in periods of high unemployment. The

18 There are of course other differences in the equations. In equation 7 we add the three migration dumies $s_{1}, s_{2}$, and $s_{3}$ and aiso introduce $\mathrm{TT}_{i} / Y_{i}$. 
coefficient of UDUM is negative and significart indicating that in periods of high unemployment the whole migration function shifts domwards: the intercept is more negative, i.e., -17.62 versus -16.31 . Even in equation 7 , the primary impact (both in terms of coefficient wize and t-values) of high umemployment is on sender region income. Outmigration from province $i$ becomes nuch less responsive to $Y_{i} / E_{i}$ during pericds of high unemployment. Interesting as these results may be, it seems ruite apparent that further research is needed to isolate more fully this relationship between inigration and economic activity.

Finally, we turn to some general comments. The impact of the three shift dummies can be assessed in part by comparing equations 5 and 6 of Table 6. Their main impact is on the overall fit of the equation and not on the qualitative implications of the results. Embodying 17 variables

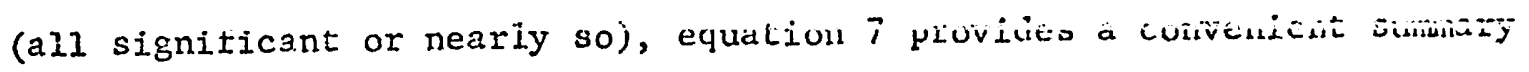
of many of the principal hypotheses of the paper. The value for $R^{2}$ indicates that this model can explain over four-fifths of the variance in migration over the sixteen-year period.

Equations 8 and 9 are included to evaluate the performance of the "gravity" model of nigration flows as well as to shed some light on the difference between our results and those of Vanderkamp. Both $Y_{i} / E_{i}$ and $\mathrm{Y}_{j} / \mathrm{E}_{\mathbf{j}}$ are divided by distance and distance itself enters the equation in reciprocal form. Essentially this is the Vanderkamp specification. We have added the three dummies $s_{1}, S_{2}$, and $S_{3}$ as well as education to the equation. The dependent variable in equation 8 is family allowance migration from $i$ to $j$ divided by the sum of the family allowance populations in $i$ and $j$, i.e., $F M_{i j} /\left(F P_{i}+F P_{j}\right)$. In equation 9 the dependent variable is the one we have been using through this section, $i_{. e}, \mathrm{FM}_{i j} / F P_{i}$. The two regressions 
were run for family ajlowance migration in 1961. This year was chosen because Vanderkamp's results [1969, Table 1] for 1961 assign approximately equal positive coefficients to both $Y_{j} / D_{i j}$ and $Y_{j} / D_{i j}$. This is also true for equation 8, i.e., .6746 vs. .6514 . Re-estimating this equation with $\mathrm{FM}_{i j} / \mathrm{FP}_{i}$ as the dependent variable yields a much increased coefficient for $\left(\mathrm{O}_{j} / \mathrm{E}_{j} / \mathrm{D}_{i j}\right.$ and an insignificant coefficient for $\left(\mathrm{Y}_{i} / \mathrm{E}_{i}\right) / \mathrm{D}_{i j} \cdot$ This positive but-insignificant impact of sender region income is consistent with the positive and also insignificant coefficient for $\mathrm{Y}_{i} / \mathrm{E}_{i}$ for $196 \mathrm{I}$ in Table 5 . It appears then that Vanderkamp's results (especially the conclusion that outmigration from $i$ is positively related to the income level in province i) stem from his definition of the dependent variable, i.e., his use of the Eravity model. Note also that the shift intercept fo: the Marjitimes to Oncario $\left(\mathrm{S}_{1}\right)$ is negative in equation 8 --the gravity model overpreilicts the

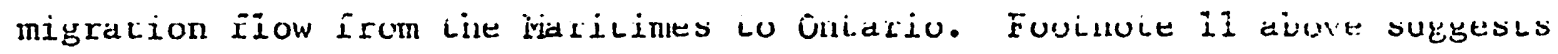
why this peculiar result is likely to occur within the context of a gravitytype formulation.

\section{Conclusion}

In lieu of summarizing the results of the paper the reader is asked to refer to the fourteen hypotheses presented in Part II of the paper. AlI have received empirical verification although the degree of substantiation varies with the particular hypothesis. Migration is an econonic variable, this much is clear. And migration is becoming more efficient over time. Workers do respond to interprovincial earnings differentials and differentials in provincial unemployment rates in a manner that is conducive to efficient resource allocation. In this sense, then, migration tends to alleviate provincial economic inequalities. However, intergovernmental 
transfers, total federul trunsfers, and memployment insurance paymeris serve to inhibit nigration and within the narrow framework we have adopted they contribute to majntaining inequality among provinces.

Unfortunateiy our results do not permit definite conclusions concejning the relationship between migration and economic adjustment. For example, unemployment in province i tends to increase the outmigration of the labor force of $i$. But who moves?--the unemployed? Our data do not shed light on this important question. In recent years, Saskatchewan has had the lowest unemployment rate in Canada. It would appear that the very high mobility rate for the Saskatchewan labor force (Tables A.I and A.2 and also variable $\mathrm{S}_{3}$ in our equations indicate the degree of mobility) can in large measure explain this. Can the low outmigration rate for Quebec explain its relatively high unemployment rate? Underlying all our analyses is the assumption that mobility contributes to jessening regional econoinic inequalities. But even this has been questioned. Myrdal [1957, p. 27], for example, states:

The localities and regions where economic activity is expanding will attract net immigration from other parts of the country. As migration is always selective, at least with respect to the migrant's age, this movement by itself tends to favour the rapidly growing comminities and disfavour the others.

Our results indicate that migration is selective not only with respect to age but as well with respect to education level. The implication of Myral's remarks is that because of migration the "have-not" provinces are left with an older and less educated labor force, not at ali conducive to lessening regional differentials. To the extent that this is indeed the case there appears to be a role for manpower folicies to interfere with incentives to ensure that the "right" people move. In sum, then, there is a great need 
for future research in the whole area of econonic: adjustment and in particular in the relationship between migration and economic adjustment. Hopefully this paper provides a firm basis on which future research can build. We conclude with a bit of casual empiricism relating to the adequacy of migration. Table 7 below ranks the provinces in order of income (lowest has rank $I$ and highest has rank j.0). The second row ranks the provinces by overall migration rate (highest has rank 1 and lowest rank 10). A naive 19 view of the "adequacy" of migration would suggest that provinces with relatively low incomes should have relativeiy high outmigration rates. Row 3 is obtained by subtracting row 2 from row 1 . A value of zero in row 3 implies a neutrality of sorts--the province's income rank is equal to its migration rank. A positive value in row 3 indicates that the particular province migrates more than its income rank would require. And conversely for a negative value. Fwon thnugh it ic true that if rar ? ansictad as. tirely of zeros this would not, of itself, be evidence that migration is adequate for economic adjustment one can, nevertheless, get a rough reading of relative provincial migration adequacy from Table 7 . The only positive values in the table occur west of Ontario. But these are the higher income provinces. The five provinces in the lower half of the income spectrum have negative or zero values in row 3. In particular, Quebec, Newfoundland and New Brunswick have "inadequate" outmigration rates in terms of our

${ }^{19}$ It is a naive approach for many reasons, one of which is that we do not include migration into each of the provinces. 
Table 7

A NAIVE APPROACIY TO THE ADEQUACY OF INTERPROVINCIAL MIGRATION

\begin{tabular}{|c|c|c|c|c|c|c|c|c|c|c|c|}
\hline Row & & NfId. & P.E.I. & N.S. & N.B. & Que. & ont. & Man. & Sask. & Alta. & B.C. \\
\hline & Income Rank ${ }^{*}$ & 3 & 1 & 4 & 2 & 5 & 9 & 6 & 7 & 8 & 10 \\
\hline & Migration Rank & 8 & 1 & 4 & 5 & 10 & 9 & 3 & 2 & 6 & 7 \\
\hline 3. & Row 1 - Row 2 & -5 & 0 & 0 & -3 & -5 & 0 & +3 & +5 & +2 & +3 \\
\hline
\end{tabular}

* Lowest value for $\mathrm{X}_{i} / \mathrm{E}_{i}$ has rank 1 .

tx* Highest value for overall outmigration rate has rank 1 .

Source: Values for $Y_{i} / E_{j}$ and overall outmigration ratios are the 16 year averages from the Family Allowance data set.

simpliste approach. 20 Therefore, even though we have demonstrated in this paper that most of the interprovincial migration that does occux can be explained in terms of resource allocation considerations, we propose, for future research, the tentative hypothesis that these interprovincial flows are not adequate for purposes of regional economic adjustment.

${ }^{20}$ It is of considerable interest that James $w$. Parker, the newly elected head of the 750-member Newfoundland Board of Trade, recently stated that Newfoundland would be better off if it had 50,000 of its people leave for the mainland in each of the next three years rather than the normal flow of approximately 5,000 persons. Naturally, Mr. Parker indicates that it is the unemployed or underemployed that have "got to move". (Globe and Mail. Feb. 6, 1970, p. B1). 
Becker, G. S. Puman Capital. (New York: Columbia University Press, 1964).

Courchene, T. J. "Lnemployrert Transfers and Interprovincial Migration" (mineo, 1969).

- "An Analysis of: Canatian Regional Economic Characteristics with Special Rmphesis on Regional Unemployment Rates," Research Report 7015, Department: of Economics, University of Western Ontario (1970).

Denton, F. 'T. An Amalysis of Interregional Differences in Manpower Ut:ilization and Earnings. Staff Study No. I5, Econonic Council of Canada, Ottawa: Queen's Jrinter, 1966.

Hunter, I. C. and G. L. Reid. Urban Worker Mobility, OECD, $196 \%$.

McInnis, M. "Ihe Trend of Regional Income Differentials in Cansda", Canadian JournaI of Economics, Vol. 1, No. 2 (May, 1968) Pp. $440-470$.

- "Provincial Migration and Differential Economic Opportunity", Chapter 5 of L. O. Stone, Migration in Canada, Reziorel Asispects. 1961 Census ronograph, D.B.S. (Ottawa: Queen's Printer, 1969).

Myrda1, G. Econcmic Theory and Under-developed Regions (Lundon, 1957).

Parai, L. Immigration and Emigration of Professional and stillad fianpores during the pooc-ing Pertod. Special Study No. 1, Ecriomic Couacil of Canada (ottawa: Quean's Printer, 1965).

Schwartz, A. "Migration and Iife Span Earnings", Unpublished Pu.i. dissertation, University of Chicago: Department of Econctics, 1960.

Scott, A. D. "A Note on Grants in Federal Countries", Economica. (November, 1950) pp. 416-422.

Sjazstad, L. "The Costs and Returns of. Human Migration", Journal of Political Economy, LXX, No. 5 (October, 1962, Supplement).

Stone, L. O. Migration in Canada, Regional Aspects. 1961 Census of Canata Monograph, D.B.S. (Ottawa: Queen's Printer, 1969).

Vanderkamp, John. "Interregional Mobility in Canada: A Study of the Tine Pattern of Migration", Canadian Journal of Economics. Vol. I, No. 3 (August, 1968) pp. 595-608.

- Migration Flows and their Determinants, and the Effects of Return Migratjon", Discussion paper 22, Department of Economics, University of British Columbia (July, 1969). 


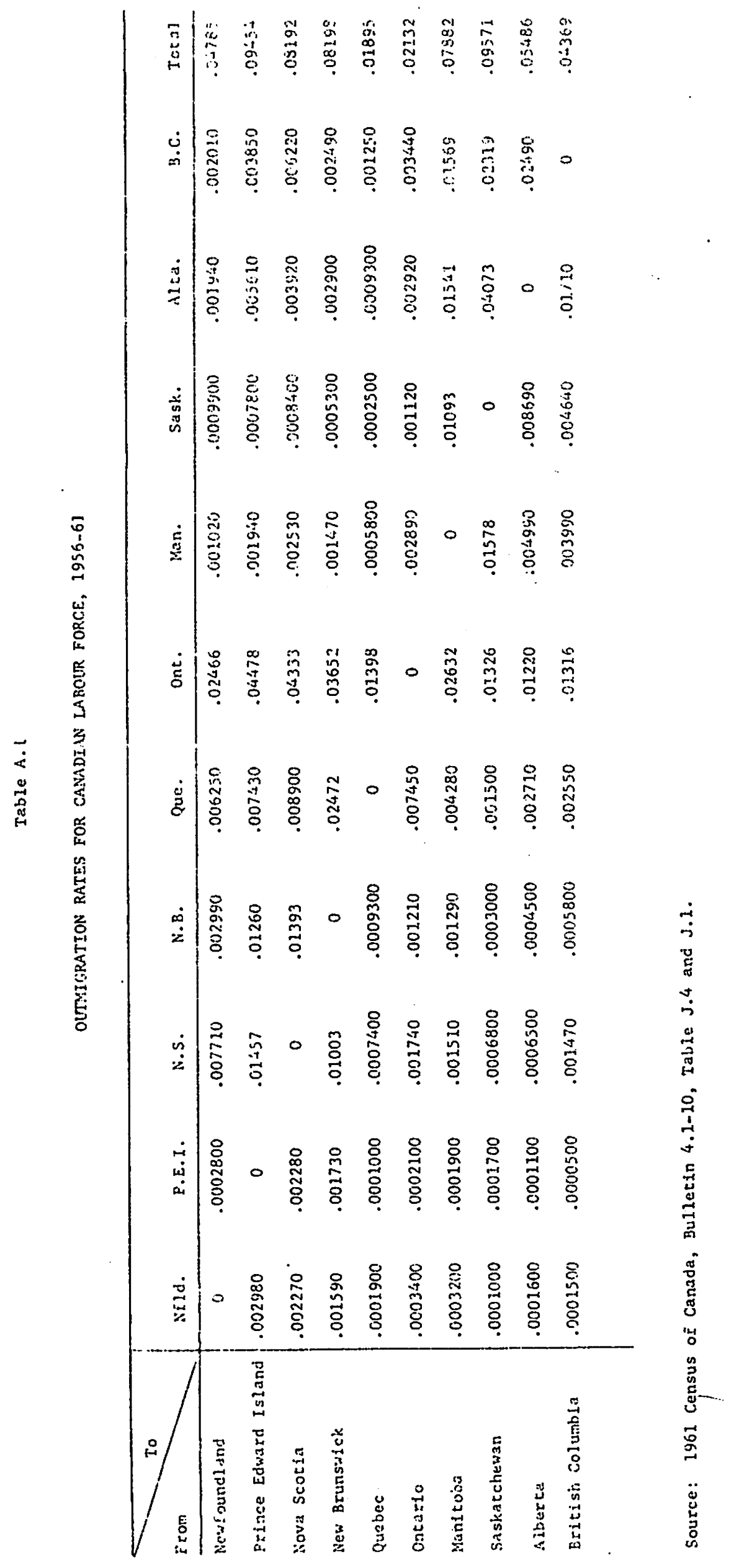



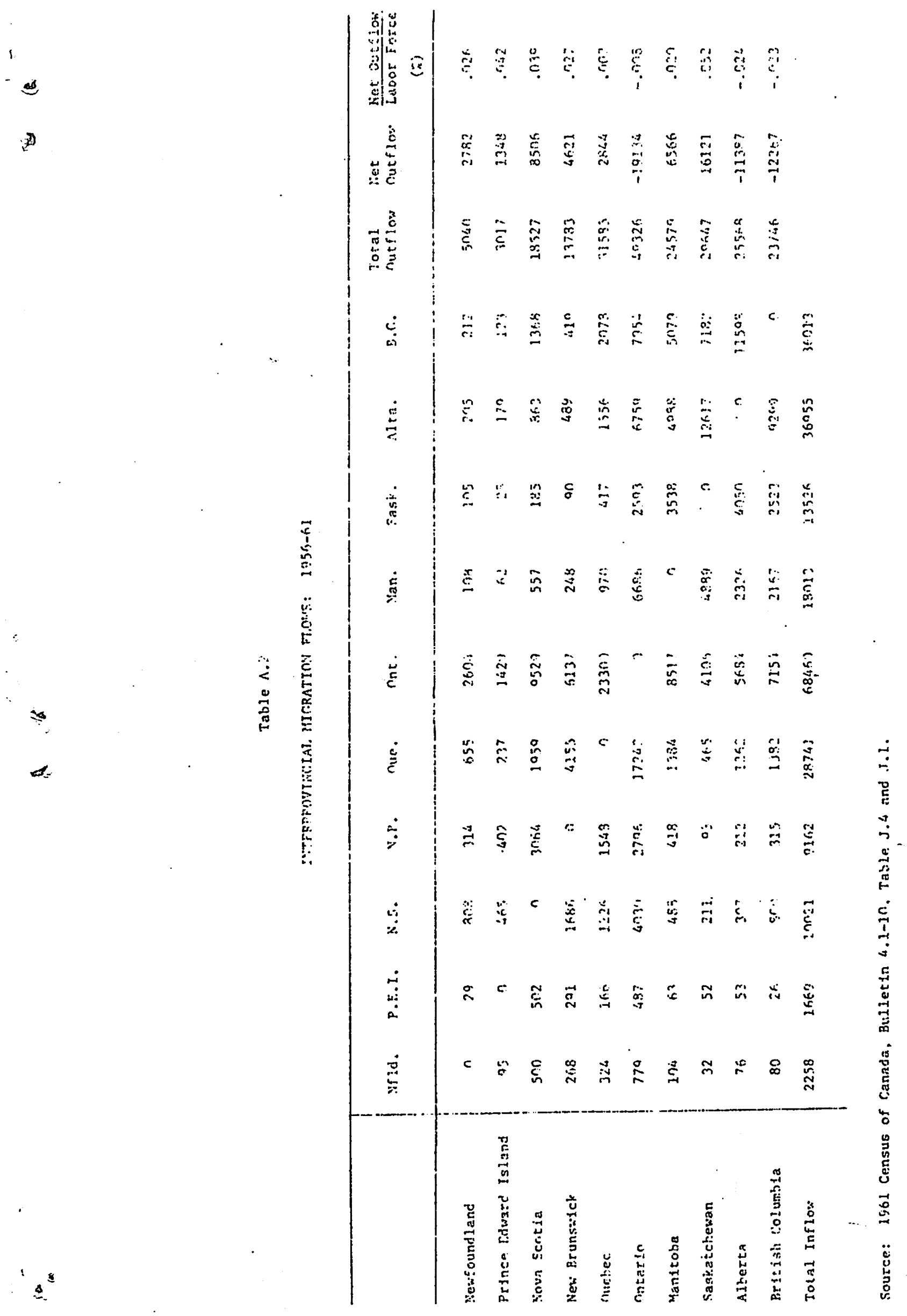